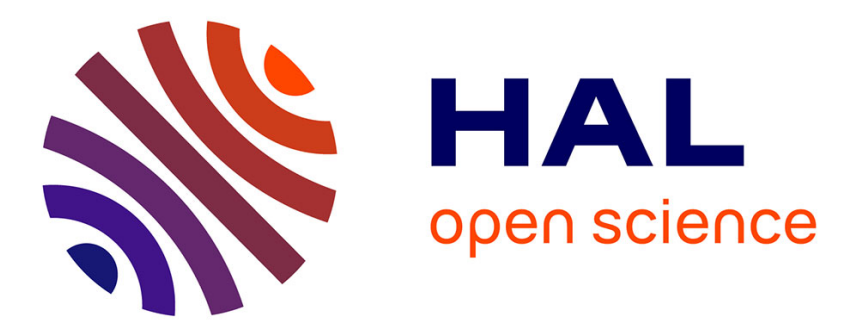

\title{
Shift happens! Adjusting stage-discharge rating curves to morphological changes at known times
}

V. Mansanarez, Benjamin Renard, Jérôme Le Coz, M. Lang, M. Darienzo

\section{To cite this version:}

V. Mansanarez, Benjamin Renard, Jérôme Le Coz, M. Lang, M. Darienzo. Shift happens! Adjusting stage-discharge rating curves to morphological changes at known times. Water Resources Research, 2019, 55, pp.2876-2899. 10.1029/2018WR023389 . hal-02609391

\section{HAL Id: hal-02609391 https://hal.inrae.fr/hal-02609391}

Submitted on 16 May 2020

HAL is a multi-disciplinary open access archive for the deposit and dissemination of scientific research documents, whether they are published or not. The documents may come from teaching and research institutions in France or abroad, or from public or private research centers.
L'archive ouverte pluridisciplinaire HAL, est destinée au dépôt et à la diffusion de documents scientifiques de niveau recherche, publiés ou non, émanant des établissements d'enseignement et de recherche français ou étrangers, des laboratoires publics ou privés. 


\section{Water Resources Research}

\author{
RESEARCH ARTICLE \\ 10.1029/2018WR023389 \\ Key Points: \\ - A general and hydraulically based \\ method replaces manual shift \\ corrections for sudden rating \\ changes \\ - Gaugings are never repeatedly used \\ across periods, but information does \\ transfer between periods \\ - The generality of the method is \\ illustrated with two contrasting \\ study cases
}

Supporting Information: - Supporting Information S1

Correspondence to:

J. Le Coz,

jerome.lecoz@irstea.fr

Citation:

Mansanarez, V., Renard, B., Le Coz, J., Lang, M., \& Darienzo, M. (2019).

Shift happens! Adjusting

stage-discharge rating curves to morphological changes at known times. Water Resources Research, 55 , 2876-2899. https://doi.org/10.1029/ 2018WR023389

Received 28 MAY 2018 Accepted 11 MAR 2019

Accepted article online 19 MAR 2019

Published online 8 APR 2019

(C)2019. American Geophysical Union. All Rights Reserved.

\section{Shift Happens! Adjusting Stage-Discharge Rating Curves to Morphological Changes at Known Times}

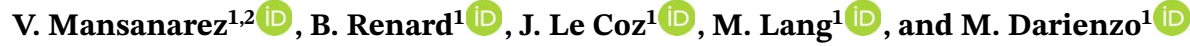 \\ ${ }^{1}$ Irstea, UR RiverLy, Villeurbanne, France, ${ }^{2}$ Department of Physical Geography, Stockholm University, Stockholm, \\ Sweden
}

Abstract Establishing streamflow time series in unstable rivers is challenged by changes in the stage-discharge relation after floods. Then, the field hydrologist must develop a new stage-discharge rating curve using new calibration data but also using some information from previous calibration data and previous rating curves. The process includes a large amount of informal expert knowledge and hydraulic assumptions seldom made explicit. This paper develops a stage-period-discharge (SPD) model based on the physical interpretation of changes in the stage-discharge relation across a series of stability periods defined by known dates and times. Using simple hydraulic equations, the user provides prior knowledge on the controls, their static and varying parameters, and their possible changes. As a single model is used for all the periods, the estimation of all rating curves can be performed in one go: All gaugings hence provide information to estimate the static parameters and the varying parameters for the relevant periods. Bayesian inference is used, providing a natural way to include prior knowledge and to quantify uncertainty. The generality and some key properties of the method are demonstrated through application to two hydrometric stations, differing in hydraulic configuration and in number and type of changes. Specific experiments demonstrate the ability of the SPD model to transfer information across periods.

Consequently, rating curves are more precisely estimated than by separately estimating them for each period. The SPD model provides a hydraulically based, transparent, and user-friendly approach to replace manual shift corrections traditionally applied in operational practice, with a quantification of uncertainties.

\section{Introduction}

\subsection{Changes in the Hydrometric Rating Curves}

Among the most important variables in hydrology, river discharge cannot be measured continuously. Most often, the discharge time series used by hydrologists result from the transformation of quasi-continuous measurements of water level, also known as stage, via a stage-discharge relation, known as the rating curve (e.g., World Meteorological Organization WMO, 2010). The rating curve must be estimated at each hydrometric station from occasional stage-discharge measurements (called gaugings) and some considerations on the hydraulic controls which physically determine the stage-discharge relation (e.g., Réméniéras, 1949). The process of building a rating curve is affected by many sources of uncertainty, including the imperfection of the specified rating curve equation, the measurement uncertainty of calibration gaugings, and the uncertainty in estimated parameters. Rating curve uncertainty impacts any analysis that makes use of discharge time series: flood frequency analysis (e.g., Steinbakk et al., 2016), hydrological model calibration (e.g., Sikorska \& Renard, 2017), real-time flood forecasting (e.g., Ocio et al., 2017), hydrological change detection (e.g., Juston et al., 2014; Lang et al., 2010), hydrological signatures (e.g., Westerberg \& McMillan, 2015), among many others. Consequently, quantifying rating curve uncertainty and using it in decision making may lead to better decisions, as illustrated by McMillan et al. (2017). Nevertheless, discharge time series are usually provided without quantitative uncertainties (Hamilton \& Moore, 2012).

A major challenge to streamflow data accuracy comes from rating changes. Ibbitt and Pearson (1987) computed how the streamflow uncertainty varied with the frequency of rating changes and the frequency of gaugings at seven hydrometric stations with unstable river channels. They concluded that ignoring rating changes was the dominant source of uncertainty of streamflow data. Rating changes are caused by the modification of the physical features controlling the stage-discharge relation: for instance, modification of the geometry or the roughness of the main channel and destruction or reshaping of a gravel riffle after a 
flood. Such modifications induce changes in the rating curve parameters and possibly in the structure of its equation. The processes leading to these modifications are numerous and complex (Herschy, 1995): bed evolution, vegetation growth, debris/ice jams, dike break, etc. In this study, we focus on the widespread rating changes due to morphological evolution induced by floods. The associated physical mechanisms are not detailed here, but comprehensive reviews can be found in textbooks (e.g., Ferreira da Silva \& Yalin, 2017; Schumm, 1977).

Recently, several methods for quantifying rating curve uncertainty have been introduced in the scientific literature, solving some of the limitations of the standardized method (WMO, 2010). Typically, among the seven methods compared by Kiang et al. (2018), only a few had some ability to account for rating changes. McMillan and Westerberg (2015) considered that the existence of unknown rating changes induces epistemic rating curve errors. They proposed a method to quantify the resulting uncertainty and add it to other sources of rating curve uncertainty. Dynamic approaches proposed by Reitan and Petersen-Øverleir (2011), Westerberg et al. (2011), Guerrero et al. (2012), or Morlot et al. (2014) attempt to derive rating curves varying with time in a continuous way, based on the premise that the stage-discharge relation is itself evolving continuously.

As rating changes often happen during episodic floods, models assuming sudden rating changes between stability periods of time are more widespread than dynamic models in the operational practice. This approach requires solving two main issues: detecting the dates and times of changes and estimating the successive static rating curves with their associated uncertainties.

Several methods exist for sudden change detection. The most common approach in operational practice is to detect changes when gaugings depart from the current rating curve by more than some predefined threshold, or when successive gauged discharges are systematically above or below the current rating curve (Puechberty et al., 2017; Rainville et al., 2016; Rantz, 1982). In a similar vein, Morlot et al. (2014) defined stability periods by applying a segmentation procedure (Hubert et al., 1989) to the residuals between gaugings and a time-invariant mean rating curve. An alternative, and perhaps overlooked, approach is to use information beyond the gaugings to define stability periods. For instance, McMillan et al. (2010) started a new period after every occurrence of a flood larger than the 0.5 -year flood.

\subsection{Methods for Adjusting Rating Curves to Shifts}

Once the times of the rating changes have been identified, the shape and parameters of the rating curve have to be adjusted for each stability period. Several alternative methods can be found in operational procedures and in the scientific literature, based on differing assumptions.

Developing each rating curve independently from scratch (e.g., Coxon et al., 2015; Watson et al., 2016) is only feasible at stations where gaugings are produced frequently compared to the occurrence of changes. Consequently, the estimation of a new rating curve is often constrained by reusing selected gaugings from other stability periods: high-flow gaugings (e.g., McMillan et al., 2010; Puechberty et al., 2017), recent gaugings (e.g., Guerrero et al., 2012; Westerberg et al., 2011), hydraulically similar gaugings (e.g., Morlot, 2014), or fictitious gaugings used as a high-flow convergence point (e.g., Morlot et al., 2014). The reuse of gaugings across several periods implicitly assumes that the corresponding controls are not varying substantially, while other controls, low-flow controls typically, are varying. The validity of this assumption depends on the site-specific hydraulic configuration.

Another approach is to derive the shifted rating curve by modifying only some selected properties of a base rating curve, as done in the "shift corrections" method commonly used by operational services in North America (Kennedy, 1984; Rantz, 1982; WMO, 2010). In a segment of the base rating curve, discharge $Q$ is usually computed as a power function of flow depth, which is the difference between water stage $h$ and an offset $b$ : $Q(h)=a(h-b)^{c}$ with $a$ and $c$ being the coefficient and the exponent of the power function, respectively. Then, the flow depth is corrected by a stage variable shift $s(h)$ as

$$
Q(h)=a[h-b+s(h)]^{c}
$$

Similar to the U.S. Geological Survey procedures (T. A. Kenney, personal communication, April 2017), the Water Survey of Canada (Rainville et al., 2016) considers three empirical types of stage variable shifts: "constant," "knee bend," and "truss" shifts (Figure 1). Based on expert knowledge on the controls at a site and 

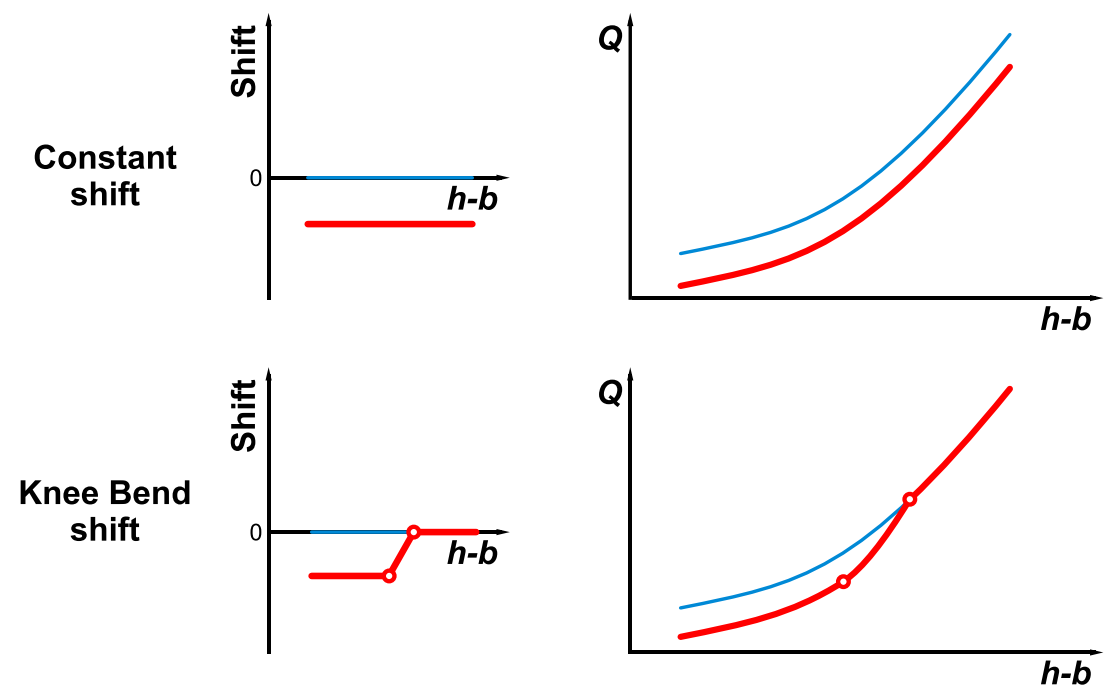

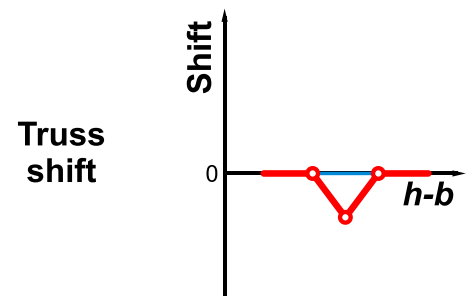

(a)

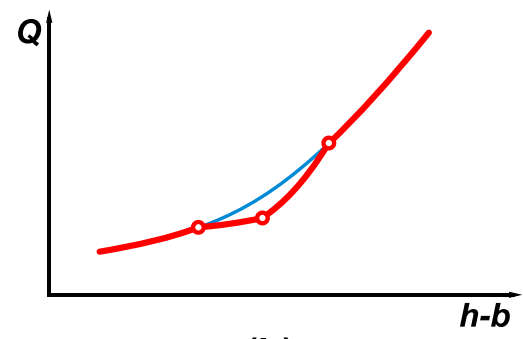

(b)

Figure 1. Shift correction methods used by the Water Survey of Canada: (a) shift (offset correction) as a function of flow depth $h-b$; (b) base (blue) and shifted (red) rating curves (modified from Rainville et al., 2016).

their modification, and based on the departures of gaugings from the base rating curve, the field hydrologist has to select a type of stage variable shift $s(h)$ and estimate its parameters. Typically, constant shifts are applied after simple aggradation or degradation of the whole channel, whereas knee bend shifts are used to adjust the low-flow section control when the overall geometry of the channel control is assumed to be unchanged. Less common, truss shifts are used to reflect a disturbance at a specific range of stage, for example, a tree falling across a channel or the slumping of a river bank.

The shift corrections discussed above correspond to assuming that only some selected parameters of the base rating curve are changing. In order to avoid the manual estimation of the shift corrections, some research methods (e.g., Guerrero et al., 2012; Juston et al., 2014; Reitan \& Petersen-Øverleir, 2011) automatically estimated the varying parameters of the rating curve equation, including parameters other than offsets. Not all parameters are necessarily varying in time: Some of them may remain static, and Reitan and Petersen-Øverleir (2011) highlight the hydraulic hypotheses associated with this choice. Unfortunately, these specific hydraulic hypotheses on the nature of the control changes are not always stated explicitly. The same issue applies to defining the type of stage variable shift in the aforementioned operational procedures.

A last approach is to compute the new rating curve using topography monitoring data and a hydraulic model (e.g., Balasch et al., 2010; Di Baldassarre \& Claps, 2011; Leonard et al., 2000; Naulet et al., 2005). The main advantage of such methods is that direct measurements of the changes in the river geometry are used to compute the corresponding rating changes using an explicit and objective hydraulic interpretation. However, the routine application of numerical modeling to manage rating changes in operational practice is challenged by the costs of field topography surveys and of the expertise required by computational techniques.

\subsection{Objectives}

While the temporal dynamics of rating changes and parameter estimation methods have received much attention from research groups, there have been few advances on hydraulically consistent methods for updating the shape and parameters of new rating curves after a series of shift episodes. Operational methods 
such as the reuse of high-flow gaugings, high-flow convergence points, and shift corrections are based on hydraulic assumptions that are rarely made explicit. Moreover, they usually require some manual fitting which makes results operator-sensitive and uncertainty quantification challenging.

This paper focuses on sudden rating curve changes, typically induced by a morphogenic flood. We further make the restrictive assumption (discussed in more depth in section 5.1) that the dates of change, or equivalently the stability periods, are known. Under this set of hypotheses, the main objectives of this paper are the following:

1. To formulate a rating curve model describing the evolution of the stage-discharge relation across stability periods. The hydraulic hypotheses behind this model are exposed and discussed. Since the stability periods are assumed to be known, they are considered as an additional input to the model, which is therefore named a stage-period-discharge (SPD) model.

2. To derive a Bayesian framework to estimate the SPD model based on uncertain gaugings and available hydraulic knowledge. Special emphasis is given to uncertainty quantification and the ability to transfer information between periods.

3. To illustrate some key properties of the SPD model through two contrasting case studies, differing in their hydraulic configuration and in the number and type of changes.

The remainder of the paper is organized as follows. Section 2 describes the formulation of the SPD model and the underlying hydraulic hypotheses. Section 3 derives the Bayesian estimation framework, including the likelihood function carrying the information brought by uncertain gaugings and the prior distribution used to integrate existing hydraulic knowledge into the estimation process. Case studies based on two contrasting hydrometric stations are proposed in section 4. The discussion in section 5 discusses current limitations and avenues for improvement, and the concluding section 6 summarizes the main findings arising from this paper.

\section{Formulation of the SPD Model}

The aim of this section is to derive the SPD model used to describe the evolution of the stage-discharge relation across several stability periods, that is, periods of time separated by sudden change times. We start by formulating the rating curve equation for one given period (section 2.1) before proposing an SPD model describing how this rating curve changes across periods (section 2.2).

\subsection{Hydraulic Configuration and Rating Curve Formulation}

Depending on the flow and site complexity, the stage-discharge relation at a given hydrometric station often results from the succession and addition of several hydraulic controls, which requires the development of segmented rating curves (Le Coz et al., 2014; Petersen-Øverleir \& Reitan, 2005).

For each control, the relation between stage $h$ and discharge $Q$ can often be approximated as a power function of the form $Q(h)=a(h-b)^{c}$. Parameters $a, b$, and $c$ (coefficient, offset, and exponent) are related to the type of control and its physical characteristics. Typically, low-flow section controls can often be approximated by a rectangular weir formula:

$$
Q(h)=\underbrace{C_{r} B_{w} \sqrt{2 g}}_{a}(h-b)^{3 / 2}
$$

where $C_{r}[-]$ is a discharge coefficient $(\approx 0.4), B_{w}(\mathrm{~m})$ is the weir perpendicular-to-flow width, $g\left(\mathrm{~m} / \mathrm{s}^{2}\right)$ is the gravity acceleration $\left(\approx 9.81 \mathrm{~m} / \mathrm{s}^{2}\right), b(\mathrm{~m})$ is the weir crest elevation, and $c=3 / 2(-)$ is the exponent for a rectangular weir. Similarly, for wide rectangular channels, the following form of the Manning-Strickler equation holds:

$$
Q(h)=\underbrace{K_{S} B_{c} \sqrt{S_{0}}}_{a}(h-b)^{5 / 3}
$$

where $K_{S}\left(\mathrm{~m}^{1 / 3} / \mathrm{s}\right)$ is the Strickler flow resistance coefficient, $B_{c}(\mathrm{~m})$ is the channel width, $S_{0}(\mathrm{~m} / \mathrm{m})$ is the bed slope, $b(\mathrm{~m})$ is the mean bed elevation along the controlling reach, and $c=5 / 3(-)$ is the exponent for a wide rectangular channel. 
Before change

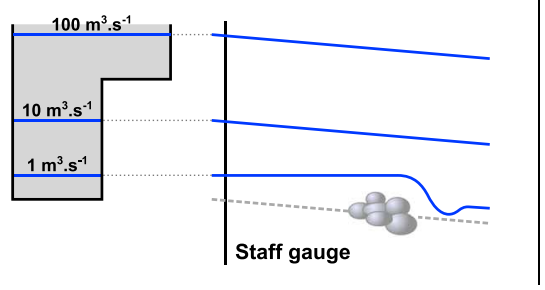

Overall change

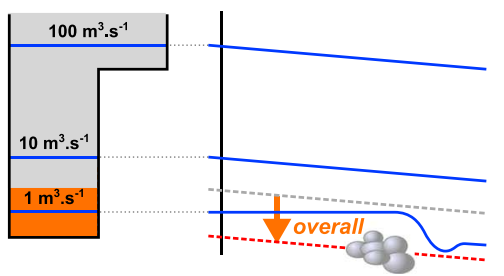

\section{Overall + local changes}

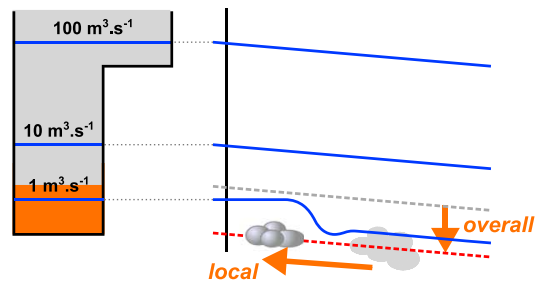

Figure 2. Schematic illustration of a hydraulic configuration subject to changes. In each panel, the right part shows the longitudinal profile (riverbed and water surface corresponding to several stages) and the left part shows the cross section at the staff gauge.

The rating curve equation can then be derived by describing how hydraulic controls succeed or add up to each other. As an illustration, consider the frequent configuration comprising three successive controls (see left panel in Figure 2): (i) a low-flow section control (typically a natural riffle or a weir); (ii) the main channel control; and (iii) a floodway control that adds up to the main channel control. Neglecting the head losses due to the interaction of the compound channel flows, we follow a divided-channel approach, and discharges in the main channel and in the floodway are simply added. The full rating curve equation for the three-control configuration considered here can be written as

$$
Q(h)=\left\{\begin{array}{lr}
a_{1}\left(h-b_{1}\right)^{c_{1}}, \text { if } \kappa_{1} \leq h<\kappa_{2} & \text { (low flow section control) } \\
a_{2}\left(h-b_{2}\right)^{c_{2}}, \text { if } \kappa_{2} \leq h<\kappa_{3} & \text { (main channel) } \\
a_{2}\left(h-b_{2}\right)^{c_{2}}+a_{3}\left(h-b_{3}\right)^{c_{3}}, \text { if } h \geq \kappa_{3} & \text { (main channel + floodway) }
\end{array}\right.
$$

where $\kappa_{1}<\kappa_{2}<\kappa_{3}$ are the activation stages for each control. This three-control equation is a particular case of the more general equation involving $N_{c}$ controls (see Le Coz et al., 2014, for an in-depth presentation):

$$
Q(h)=\sum_{i=1}^{N_{c}}\left(\mathbb{1}_{\left[\kappa_{i} ; \kappa_{i+1}\right]}(h) \times \sum_{j=1}^{N_{c}} M(i, j) \times a_{j}\left(h-b_{j}\right)^{c_{j}}\right)
$$

where $\mathbb{1}_{A}(h)$ is the indicator function of a set $A$ and $M(i, j)$ is the control matrix, equal to 1 if control $j$ is active in the $i$ th stage range $\left[\kappa_{i} ; \kappa_{i+1}\right]$ and 0 otherwise. In the three-control example above, $M=\left(\begin{array}{lll}1 & 0 & 0 \\ 0 & 1 & 0 \\ 0 & 1 & 1\end{array}\right)$.

Finally, note that the unknown parameters of the rating curve are $\left(b_{j}, a_{j}, c_{j}\right)_{j=1 \ldots N_{c}}$ but that the activation stages $\kappa_{j}$ are deduced by continuity of the rating curve. When a control is added to active control(s) (e.g., floodway added to the main channel), the continuity condition necessarily leads to $\kappa_{j}=b_{j}$. When a control replaces an active control, $\kappa_{j}$ is a solution of the following equation:

$$
a_{j}\left(\kappa_{j}-b_{j}\right)^{c_{j}}=a_{j-1}\left(\kappa_{j}-b_{j-1}\right)^{c_{j-1}}
$$

This equation has no explicit solution and has to be solved numerically using, for example, the Newton-Raphson method. Depending on parameter values, there can be zero, one or two solutions. If two solutions exist, the highest one is selected because the smallest solution creates a discontinuity that does not make physical sense (cf. Appendix A for mathematical details).

\subsection{Rating Changes}

The generic rating curve equation (5) can be modified to reflect the changes occurring between $P$ stability periods. Without loss of generality, periods are numbered from the most recent to the oldest one. A SPD model can be formulated as a model with two input variables: the stage $h$ and the period index $k$. This corresponds to the hypothesis that the stability periods are known and can therefore be considered as an input to the model. An SPD version of equation (5) can for instance be obtained by simply assuming that all rating curve parameters $\left(a_{j}^{(k)}, b_{j}^{(k)}, c_{j}^{(k)}\right)$ are period specific:

$$
Q(h, k)=\sum_{i=1}^{N_{c}}\left(\mathbb{1}_{\left[\kappa_{i}^{(k)} ; \kappa_{i+1}^{(k)}\right]}(h) \times \sum_{j=1}^{N_{c}} M(i, j) \times a_{j}^{(k)}\left(h-b_{j}^{(k)}\right)^{c_{j}^{(k)}}\right)
$$


Since all the parameters are changing between periods, this SPD model is equivalent to establishing a new rating curve from scratch for each period. This can be further constrained by assuming that some parameters are static, that is, they do not depend on the period. In turn, this corresponds to the physical assumption that some properties of the hydraulic controls do not change between periods. To further illustrate this, consider the three-control rating curve of equation (4) and its SPD version given below:

$$
Q(h, k)=\left\{\begin{array}{lr}
a_{1}\left(h-b_{1}^{(k)}\right)^{c_{1}}, \text { if } \kappa_{1}^{(k)} \leq h<\kappa_{2}^{(k)} & \text { (low flow section control) } \\
a_{2}\left(h-b_{2}^{(k)}\right)^{c_{2}}, \text { if } \kappa_{2}^{(k)} \leq h<\kappa_{3} & \text { (main channel) } \\
a_{2}\left(h-b_{2}^{(k)}\right)^{c_{2}}+a_{3}\left(h-b_{3}\right)^{c_{3}}, \text { if } h \geq \kappa_{3} & \text { (main channel + floodway) }
\end{array}\right.
$$

Offsets parameters $b_{1}^{(k)}, b_{2}^{(k)}$ are here assumed period specific, while all other parameters (coefficients $a_{1}, a_{2}, a_{3}$, exponents $c_{1}, c_{2}, c_{3}$, and floodway offset $b_{3}$ ) are assumed static. The underlying hydraulic assumptions are the following:

1. Static exponents $\left(c_{1}, c_{2}, c_{3}\right)$ imply that the type of control does not change (e.g., a rectangular cross-section control cannot become triangular).

2. Static coefficients $\left(a_{1}, a_{2}, a_{3}\right)$ imply that the width and discharge coefficient of the low-flow controlling riffle, and the widths, slopes, and resistance coefficients of the channels do not vary.

3. The static floodway offset $\left(b_{3}\right)$ implies that the floodway remains unchanged across periods.

4. In addition, the structure of the rating curve does not change across periods; that is, controls cannot be created or deleted.

The example SPD model of equation (8) should be modified whenever this set of assumptions is deemed unrealistic. For instance, if one suspects that the width of the low-flow controlling riffle may change, then the coefficient $a_{1}^{(k)}$ should be made period specific. The key point is that the specification of the SPD model in terms of static/period-specific parameters should be based on the hydraulic analysis of the station-just as the formulation of the rating curve equation.

\section{Bayesian Inference}

\subsection{Inference Setup and Assumptions}

Let $\boldsymbol{\beta}$ denote the unknown parameters of the SPD model, comprising static and period-specific parameters $\boldsymbol{\beta}_{\text {static }}$ and $\boldsymbol{\beta}_{\text {period }}$. For the example SPD model of equation (8), $\boldsymbol{\beta}_{\text {static }}=\left(a_{1}, c_{1}, a_{2}, c_{2}, b_{3}, a_{3}, c_{3}\right)$ and $\boldsymbol{\beta}_{\text {period }}=$ $\left(b_{1}^{(k)}, b_{2}^{(k)}\right)_{k=1 \ldots P}$. The discharge computed by the SPD model can then be written as follows:

$$
\hat{Q}=f(h, k \mid \boldsymbol{\beta})
$$

Inference on the parameters is performed using a set of gaugings $\left(\tilde{h}_{i}, \tilde{k}_{i}, \tilde{Q}_{i}\right)_{i \in \llbracket 1 ; N \|^{*}}$. Note that since the SPD model uses the period as an input variable, a gauging is a triplet comprising the period $\tilde{k}_{i}$ with which it is associated, in addition to the usual stage-discharge pair $\left(\tilde{h}_{i}, \tilde{Q}_{i}\right)$. The tilde symbol is used to denote the fact that a gauging is made up of imperfect measurements and is therefore an estimate of the real values $\left(h_{i}, k_{i}, Q_{i}\right)$. In this paper, it is assumed that all periods are correctly assigned $\left(\tilde{k}_{i}=k_{i}\right)$ and that stage errors are negligible $\left(\tilde{h}_{i}=h_{i}\right)$. The following error model is used for the gauged discharges:

$$
\tilde{Q}_{i}=Q_{i}+\epsilon_{Q, i} \quad \text { with } \quad \epsilon_{Q, i} \sim \mathcal{N}\left(0, u_{Q, i}\right)
$$

where the measurement errors $\left(\epsilon_{Q, 1}, \ldots, \epsilon_{Q, N}\right)$ are assumed mutually independent and the standard deviations $\left(u_{Q, 1}, \ldots, u_{Q, N}\right)$ (uncertainty of each gauged discharge) are assumed to be known from an uncertainty analysis of the discharge measurement process (for more details, see Le Coz et al., 2014, and references therein).

The true discharge is then written as the discharge predicted by the SPD model plus a structural error:

$$
Q_{i}=\underbrace{f\left(h_{i}, k_{i} \mid \boldsymbol{\beta}\right)}_{\widehat{Q_{i}}}+\epsilon_{f, i} \quad \text { with } \quad \epsilon_{f, i} \sim \mathcal{N}\left(0, \gamma_{1}+\gamma_{2} \hat{Q}_{i}\right)
$$


where the structural errors $\left(\epsilon_{f, 1}, \ldots, \epsilon_{f, N}\right)$ are assumed mutually independent and also independent of the discharge errors $\left(\epsilon_{Q, 1}, \ldots, \epsilon_{Q, N}\right)$. The standard deviation of the structural error is modeled as a linear function of the predicted discharge, with parameters $\boldsymbol{\gamma}=\left(\gamma_{1}, \gamma_{2}\right)$ being unknown and therefore added to the inference list. For more discussion on these assumptions, we refer the reader to Le Coz et al. (2014). Note that parameters $\boldsymbol{\gamma}$ do not depend on the period: this corresponds to assuming that while the rating curve changes between periods, the properties of the structural errors remain static. This assumption will be discussed in section 5.2.

3.2. Likelihood Computation

Combining equations (10) and (11) yields the following equation:

$$
\tilde{Q}_{i}=f\left(h_{i}, k_{i} \mid \boldsymbol{\beta}\right)+\epsilon_{Q, i}+\epsilon_{f, i} \quad \text { with } \quad \epsilon_{Q, i}+\epsilon_{f, i} \sim \mathcal{N}\left(0, \sqrt{\left(\gamma_{1}+\gamma_{2} \hat{Q}_{i}\right)^{2}+u_{Q, i}^{2}}\right)
$$

The distribution of an observed gauged discharge $\tilde{Q}_{i}$, conditional on the unknown parameters $\boldsymbol{\theta}=(\boldsymbol{\beta}, \boldsymbol{\gamma})$ and on the gauged stage $h_{i}$ and period $k_{i}$, is therefore Gaussian with mean the SPD-predicted discharge $f\left(h_{i}, k_{i} \mid \boldsymbol{\beta}\right)$ and a standard deviation combining measurement and structural uncertainties as shown in equation (12). The following likelihood is obtained:

$$
p(\tilde{\boldsymbol{Q}} \mid \boldsymbol{\theta}, \boldsymbol{h}, \boldsymbol{k})=\prod_{i=1}^{N} \phi\left(\tilde{Q}_{i} \mid f\left(h_{i}, k_{i} \mid \boldsymbol{\beta}\right), \sqrt{\left(\gamma_{1}+\gamma_{2} \hat{Q}_{i}\right)^{2}+u_{Q, i}^{2}}\right)
$$

where $\phi(z \mid m, s)$ denotes the probability density function (pdf) of a Gaussian distribution with mean $m$ and standard deviation $s$, evaluated at some value $z$.

The likelihood in equation (13) provides a built-in mechanism to associate the rating curve parameters with the relevant gaugings. Indeed, the static rating curve parameters $\boldsymbol{\beta}_{\text {static }}$ appear in all $N$ terms of the product in equation (13). Consequently, the information contained in all the gaugings is used to infer these static parameters. By contrast, parameters $\boldsymbol{\beta}_{\text {period }}^{(k)}$ specific to the $k$ th period only appear in the terms of the product involving gaugings from the $k$ th period. Consequently, only the gaugings made during the $k$ th period are informative for the period-specific parameters $\boldsymbol{\beta}_{\text {period }}^{(k)}$. This is to be contrasted with the standard operational practice of reusing some high-flow gaugings across several periods, arguing that they remain representative of the stage-discharge relation at high flows (see section 1). In the SPD model, gaugings are always assigned to a unique period and are not repeatedly used across periods: instead, the static parameters are used across periods.

\subsection{Prior Specifications}

Bayesian inference requires specifying a joint prior distribution for the vector of inferred parameters $\theta$. The joint prior pdf is factorized as follows:

$$
p(\boldsymbol{\theta})=p\left(\gamma_{1}\right) p\left(\gamma_{2}\right) p\left(\boldsymbol{\beta}_{\text {static }}\right) p\left(\boldsymbol{\beta}_{\text {period }}\right)
$$

Since little is known about structural uncertainty before having estimated the model, only order-of-magnitude considerations can generally be used for parameters $\gamma_{1}$ and $\gamma_{2}$. Parameter $\gamma_{1}$ can be interpreted as the structural standard deviation for near-zero flows: its prior distribution should span between near-zero values and values that are of the same order of magnitude as typical low flows in the studied river. Parameter $\gamma_{2}$ can be interpreted as the relative structural standard deviation at high flows: its prior distribution should therefore have its mass mostly comprised between $0 \%$ and 100\%; typical values encountered in our experience are around 5-30\%.

Prior distributions for other parameters are case specific: they depend on the physical properties of the controls (geometry, slope, friction, etc.) and the precision with which these properties are measured or estimated by expert opinion. The prior specification process for these parameters will be illustrated in more detail in the case studies (section 4); moreover, we refer the reader to Le Coz et al. (2014) for a more in-depth discussion of general principles.

In the context of changing rating curves, the specification of a joint prior distribution for period-specific parameters is not straightforward because prior information will typically not be directly available in terms of inferred parameters $\boldsymbol{\beta}_{\text {period }}$. To illustrate this issue, consider the example SPD model of equation (8), schematized in Figure 2. In this example, we consider two types of change. The first type corresponds to the scouring 
(or the filling) of the main channel over the controlling reach (with no change in the channel width). Such a change would induce a modification of the offset of the main channel control $\left(b_{2}\right)$. Moreover, because the riffle lies on the riverbed, the offset of the first low flow control $\left(b_{1}\right)$ should also be affected by the same change (middle panel in Figure 2). Such a change is therefore referred to as an overall change, noted $\delta g$. In addition to this overall scouring/filling of the main channel, the controlling riffle may also move longitudinally and its crest elevation with respect to the riverbed may also change. Consequently, the offset of the first low flow control $\left(b_{1}\right)$ may also be affected by a local change (noted $\delta l$ ), which adds to the overall change (right panel in Figure 2). However, this local change does not affect the channel controls (main channel and floodway). This configuration can be formalized as follows:

$$
\begin{cases}b_{1}^{(k)}=b_{1}^{(k-1)}-\left(\delta g^{(k)}+\delta l^{(k)}\right) & \text { incremental change in low flow control) } \\ b_{2}^{(k)}=b_{2}^{(k-1)}-\delta g^{(k)} & \text { (incremental change in channel control) }\end{cases}
$$

or equivalently, by developing this recursive relation up to period 1, used as the reference period:

$$
\begin{cases}b_{1}^{(k)}=b_{1}^{(1)}-\left(\sum_{i=2}^{k} \delta g^{(i)}+\sum_{i=2}^{k} \delta l^{(i)}\right) & \text { (cumulative change in low flow control) } \\ b_{2}^{(k)}=b_{2}^{(1)}-\sum_{i=2}^{k} \delta g^{(i)} & \text { (cumulative change in channel control) }\end{cases}
$$

An expert of the hydrometric station may be able to provide some information on the possible changes after a morphogenic flood (overall scouring/filling of the main channel and local change on the low-flow control). This information is expressed in terms of incremental changes $\delta g$ and $\delta l$, which are actually equivalent to the constant and knee bend shift corrections discussed in section 1.2 (Figure 1). As they are not parameters of the SPD model, it is necessary to transfer the prior information from incremental changes $\left(\delta g^{(k)}, \delta l^{(k)}\right)_{k=2 \ldots P}$ to inferred parameters. A Monte Carlo approach can be used to achieve this, by propagating samples from the independent prior distributions of $\left(b_{1}^{(1)}, b_{2}^{(1)}, \delta g^{(2)}, \delta l^{(2)}, \ldots, \delta g^{(P)}, \delta l^{(P)}\right)$ through equation (16), yielding samples from the joint prior distribution of offset parameters $\left(b_{1}^{(k)}, b_{2}^{(k)}\right)_{k=1 \ldots P}$. A multivariate distribution can then be fitted to these samples and used as the joint prior. A multivariate Gaussian distribution may typically be used if all marginal samples of $\left(b_{1}^{(k)}, b_{2}^{(k)}\right)_{k=1}$ are approximately Gaussian. In case non-Gaussian marginal priors are deemed more appropriate, a Gaussian copula (e.g., Renard \& Lang, 2007) may be used to combine them into a joint multivariate distribution.

\subsection{Posterior Distribution and Markov Chain Monte Carlo Sampling}

The posterior pdf can be computed up to a constant of proportionality by combining the likelihood (equation (13)) and the prior pdf (equation (14)) using Bayes' rule:

$$
p(\boldsymbol{\theta} \mid \tilde{\boldsymbol{Q}}, \boldsymbol{h}, \boldsymbol{k}) \propto p(\tilde{\boldsymbol{Q}} \mid \boldsymbol{\theta}, \boldsymbol{h}, \boldsymbol{k}) p(\boldsymbol{\theta})
$$

The posterior distribution is explored by applying a Markov chain Monte Carlo (MCMC) sampler to the unnormalized posterior (equation (17)). The MCMC sampler used in this paper is an adaptive block Metropolis sampler described in Renard et al. (2006). In short, this Metropolis sampler updates the parameter vector one component at a time and modifies the variance of the (one-dimensional) Gaussian jump distributions to maintain acceptance rates within user-specified bounds (here, $10 \%$ and $50 \%$ ). In this paper, 100,000 iterations are performed, with the first half being discarded as a burn-in period. The remaining 50,000 iterations are further thinned by only keeping one iteration every 10: this allows restricting computing time and storage issues, while not resulting in a noticeable loss of information because the raw MCMC samples are strongly autocorrelated. Convergence is checked visually.

The MCMC sampler hence generates $N_{\text {sim }}$ vectors of inferred parameters $\left(\boldsymbol{\theta}^{(i)}\right)_{i \in \llbracket 1 ; N_{\text {sim }} \rrbracket}$. This set can be used to describe the marginal and joint properties of the parameter vector $\boldsymbol{\theta}$ (e.g., posterior mean, median, standard deviation, credibility interval, and parameter correlations). The properties of any quantity derived from $\boldsymbol{\theta}$, such as the incremental changes or the rating curves for each period, can also readily be described. In addition, the parameter $\hat{\boldsymbol{\theta}}$ corresponding to the largest posterior pdf is extracted from the simulated $\left(\boldsymbol{\theta}^{(i)}\right)$ This parameter and any derived quantity are referred to as the "maximum a posteriori" estimates. 

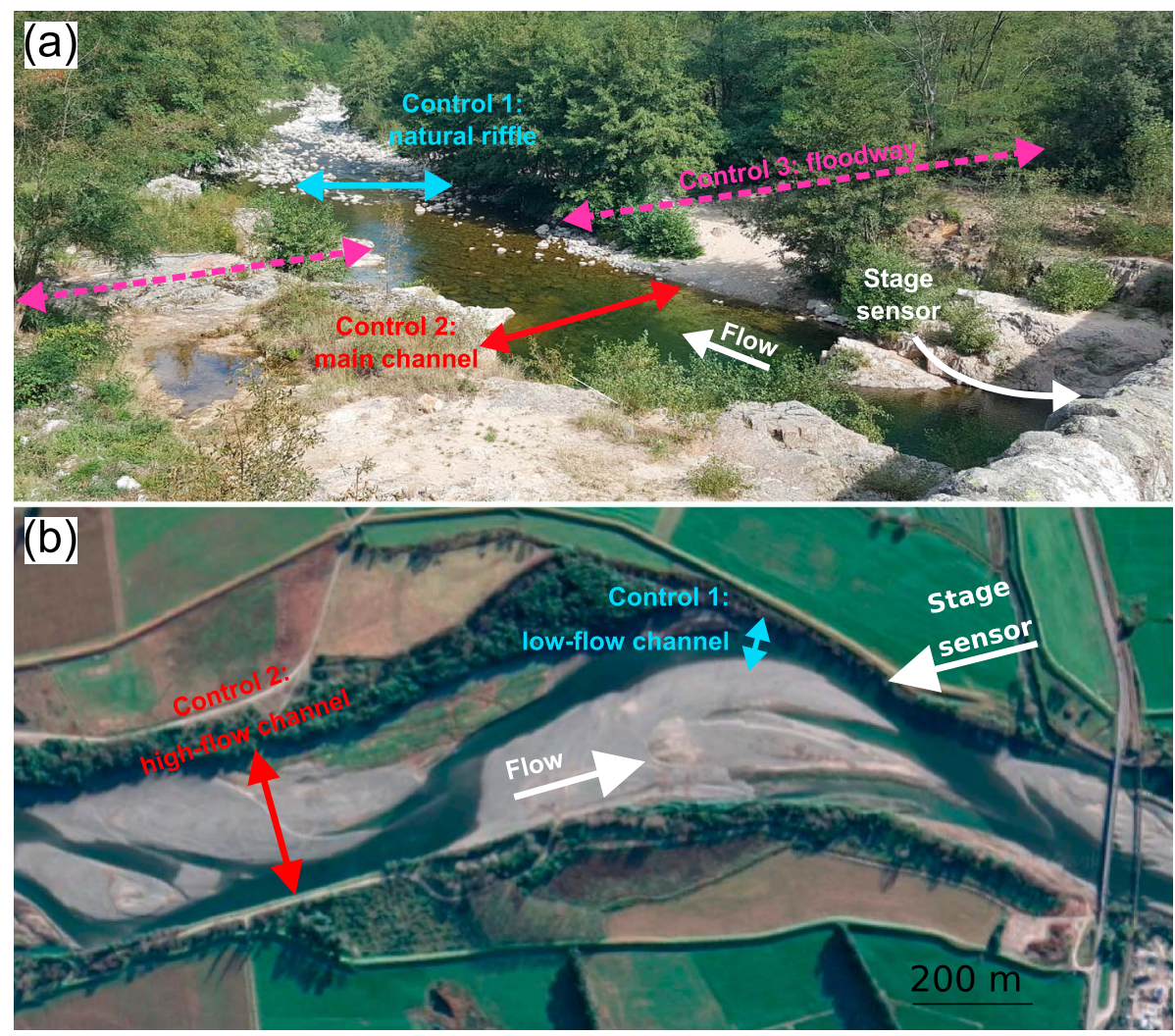

Figure 3. Presentation of the hydrometric stations used in the case studies and interpretation in terms of hydraulic controls: (a) Ardèche at Meyras, picture taken by Irstea in October 2016; (b) Wairau at Barnett's Bank, Imagery (C2019 DigitalGlobe, Map data @2019 Google.

\section{Case Studies}

\subsection{The Ardèche River at Meyras, France 4.1.1. Site Description}

The case study focuses on the Ardèche River at Meyras hydrometric station (V5004030), Mediterranean France, which monitors a catchment area of $98 \mathrm{~km}^{2}$. This station has been used by Adamovic et al. (2015) and Sikorska and Renard (2017) for hydrological modeling purposes, and we therefore refer the reader to these papers for additional general information on the station and the associated catchment. The gauge is located just under a bridge $\left(4^{\circ} 16^{\prime} 11^{\prime \prime} \mathrm{E}, 44^{\circ} 40^{\prime} 12^{\prime \prime} \mathrm{N}\right.$, Figure $\left.3 \mathrm{a}\right)$. Located approximately $50 \mathrm{~m}$ downstream from the bridge, a natural gravel riffle controls the lowest flows. A main channel replaces this riffle as the flow increases and then two floodways (one on each side) are added to the main channel for very high flows. The two floodways can be combined into an equivalent single channel control because they are activated at approximately the same stage. This corresponds to the three-control configuration described in section 2 , and the SPD model of equation (8) can therefore be applied.

The riverbed around the station changes regularly due to the intensity of flash floods. Over the period October 2001 to September 2014, the hydrometric service in charge of managing the station developed five distinct rating curves, and the associated dates of change correspond to major flood events. A total of 104 gaugings is available (mostly performed with Acoustic Doppler Current Profiler and currentmeters), leading to about 21 gaugings per period on average (minimum: 8, maximum: 33). Note that only three gaugings have been performed with water flowing in the floodway.

\subsubsection{Prior Specification}

Prior specification is performed as outlined in section 3.3, and the resulting priors are given in Table 1. Priors are first expressed in terms of physical parameters (first three columns), that is, parameters having a direct hydraulic interpretation (see Le Coz et al., 2014, for a more detailed description on this prior elicitation process). All marginal priors are assumed independent at this stage. Priors on inferred parameters are then 
Table 1

Prior Distributions Used in the Ardèche at Meyras Case Study

\begin{tabular}{|c|c|c|c|c|}
\hline Physical parameter & Meaning & Prior & Inferred parameter & Prior \\
\hline \multicolumn{5}{|c|}{ Control 1: low-flow riffle } \\
\hline$b_{1}^{(1)}(\mathrm{m})$ & Offset (period 1) & $\mathcal{N}(-0.6 ; 0.5)$ & $b_{1}^{(1)}(\mathrm{m})$ & $\mathcal{N}(-0.6 ; 0.5)$ \\
\hline$B_{w}(\mathrm{~m})$ & Riffle width & $\mathcal{L} \mathcal{N}(\ln (8) ; 0.25)$ & $a_{1}\left(\mathrm{~m}^{\frac{3}{2}} / \mathrm{s}\right)$ & $\mathcal{L} \mathcal{N}(2.65 ; 0.35)$ \\
\hline$C_{r}(-)$ & Discharge coefficient & $\mathcal{L} \mathcal{N}(\ln (0.4) ; 0.25)$ & & \\
\hline$g\left(\mathrm{~m} / \mathrm{s}^{2}\right)$ & Gravity & $\mathcal{L} \mathcal{N}(\ln (9.81) ; 0.005)$ & & \\
\hline$c_{1}(-)$ & Exponent & $\mathcal{N}(1.5 ; 0.025)$ & $c_{1}(-)$ & $\mathcal{N}(1.5 ; 0.025)$ \\
\hline \multicolumn{5}{|c|}{ Control 2: main channel } \\
\hline$b_{2}^{(1)}(\mathrm{m})$ & Offset (period 1) & $\mathcal{N}(-0.6 ; 0.5)$ & $b_{2}^{(1)}(\mathrm{m})$ & $\mathcal{N}(-0.6 ; 0.5)$ \\
\hline$B_{c_{2}}(\mathrm{~m})$ & Channel width & $\mathcal{L} \mathcal{N}(\ln (15) ; 0.2)$ & $a_{2}\left(\mathrm{~m}^{\frac{4}{3}} / \mathrm{s}\right)$ & $\mathcal{L} \mathcal{N}(3.28 ; 0.33)$ \\
\hline$K_{S_{2}}\left(\mathrm{~m}^{\frac{1}{3}} / \mathrm{s}\right)$ & Strickler coefficient & $\mathcal{L} \mathcal{N}(\ln (25) ; 0.1)$ & & \\
\hline$S_{0_{2}}(-)$ & Bed slope & $\mathcal{L} \mathcal{N}(\ln (0.005) ; 0.5)$ & & \\
\hline$c_{2}(-)$ & Exponent & $\mathcal{N}(1.67 ; 0.025)$ & $c_{2}(-)$ & $\mathcal{N}(1.67 ; 0.025)$ \\
\hline \multicolumn{5}{|l|}{ Control 3: floodway } \\
\hline$b_{3}(\mathrm{~m})$ & Offset & $\mathcal{N}(1.2 ; 0.2)$ & $b_{3}(\mathrm{~m})$ & $\mathcal{N}(1.2 ; 0.2)$ \\
\hline$B_{c_{3}}(\mathrm{~m})$ & Channel width & $\mathcal{L} \mathcal{N}(\ln (30) ; 0.2)$ & $a_{3}\left(\mathrm{~m}^{\frac{4}{3}} / \mathrm{s}\right)$ & $\mathcal{L} \mathcal{N}(3.46 ; 0.38)$ \\
\hline$K_{S_{3}}\left(\mathrm{~m}^{\frac{1}{3}} / \mathrm{s}\right)$ & Strickler coefficient & $\mathcal{L} \mathcal{N}(\ln (15) ; 0.2)$ & & \\
\hline$S_{0_{3}}(-)$ & Bed slope & $\mathcal{L} \mathcal{N}(\ln (0.005) ; 0.5)$ & & \\
\hline$c_{3}(-)$ & Exponent & $\mathcal{N}(1.67 ; 0.025)$ & $c_{3}(-)$ & $\mathcal{N}(1.67 ; 0.025)$ \\
\hline \multicolumn{5}{|c|}{ Incremental changes $(2 \leq k \leq 5)$} \\
\hline$\delta l^{(k)}(\mathrm{m})$ & Local change & $\mathcal{N}(0 ; 0.5)$ & $b_{1}^{(k)}(\mathrm{m})$ & See text \\
\hline$\delta g^{(k)}(\mathrm{m})$ & Overall change & $\mathcal{N}(0 ; 0.5)$ & $b_{2}^{(k)}(\mathrm{m})$ & See text \\
\hline \multicolumn{5}{|c|}{ Structural uncertainty parameters } \\
\hline$\gamma_{1}\left(\mathrm{~m}^{3} / \mathrm{s}\right)$ & Intercept & $\mathcal{L} \mathcal{N}(\ln (1) ; 1)$ & $\gamma_{1}\left(\mathrm{~m}^{3} / \mathrm{s}\right)$ & $\mathcal{L} \mathcal{N}(\ln (1) ; 1)$ \\
\hline$\gamma_{2}(-)$ & Slope & $\mathcal{L} \mathcal{N}(\ln (0.5) ; 1)$ & $\gamma_{2}(-)$ & $\mathcal{L} \mathcal{N}(\ln (0.5) ; 1)$ \\
\hline
\end{tabular}

Note. $\mathcal{N}(\mu, \sigma)$ and $\mathcal{L} \mathcal{N}\left(\mu_{\log }, \sigma_{\log }\right)$ stand for, respectively, the Gaussian distribution of mean $\mu$ and standard deviation $\sigma$, and the lognormal distribution whose logarithm has mean equal to $\mu_{\log }$ and standard deviation equal to $\sigma_{\log }$.

obtained using Monte Carlo propagation (last two columns). For instance, the prior for parameter $a_{1}$ is derived by propagating 100,000 samples of physical parameters $\left(B_{w}, C_{r}, g\right)$ through equation (2).

The following general comments can be made on the specified priors:

1. Lognormal priors are used for positive quantities (widths, slopes, coefficients, and resulting $\left(a_{1}, a_{2}, a_{3}\right)$ parameters).

2. Very precise priors are used for exponents $\left(c_{1}, c_{2}, c_{3}\right)$ because they only depend on the type of control (here, a rectangular riffle and two large rectangular channels).

3. Informative but not overly precise priors are used for describing the various properties of each control. As an illustration, the priors used for the main channel correspond to the following $95 \%$ uncertainty intervals: $[10 ; 22] \mathrm{m}$ for the width, [20;30] $\mathrm{m}^{\frac{1}{3}} / \mathrm{s}$ for the Strickler coefficient, and $[0.2 ; 1.3] \%$ for the slope.

4. Structural uncertainty parameters $\left(\gamma_{1}, \gamma_{2}\right)$ are weakly constrained by order-of-magnitude priors.

As explained in section 3.3, priors for the possible changes affecting offsets $\left(b_{1}, b_{2}\right)$ are expressed in terms of incremental local and overall changes. Riverbed changes during floods are very unlikely to exceed $1 \mathrm{~m}$ at that site, and even though the river has constantly degraded in recent years, it seems more conservative not to constrain the sign of the elevation changes and therefore set the prior mean to 0 . This leads to the priors expressed in terms of incremental changes $\delta l^{(k)}$ and $\delta g^{(k)}$ shown in Table 1. These priors need to be transformed into the joint prior of inferred parameters $\left(b_{1}^{(k)}, b_{2}^{(k)}\right)$, which is achieved using Monte Carlo propagation through equation (16). 
Local and global incremental change parameters

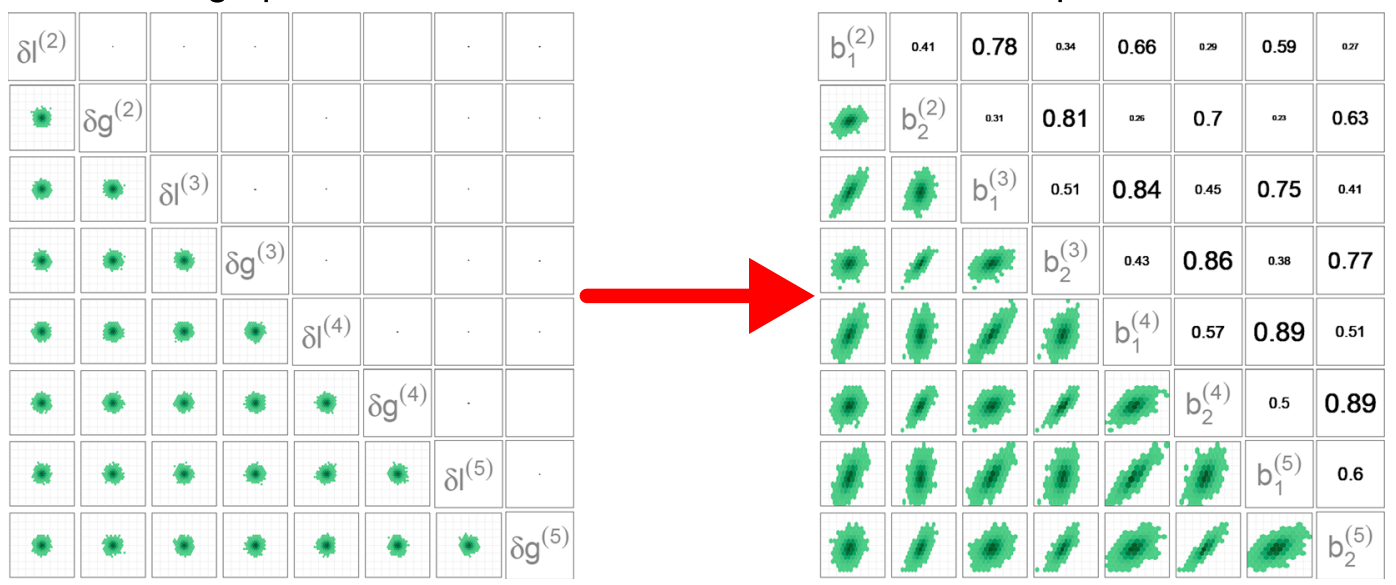

Figure 4. Ardèche case study: illustration of the transformation from a prior expressed in terms of local/overall incremental changes to the final prior for inferred parameters $\left(b_{1}^{(k)}, b_{2}^{(k)}\right)$. The upper triangular part of the matrix shows the correlations between parameters, while the lower triangular part shows scatterplots of Monte Carlo sampled values.
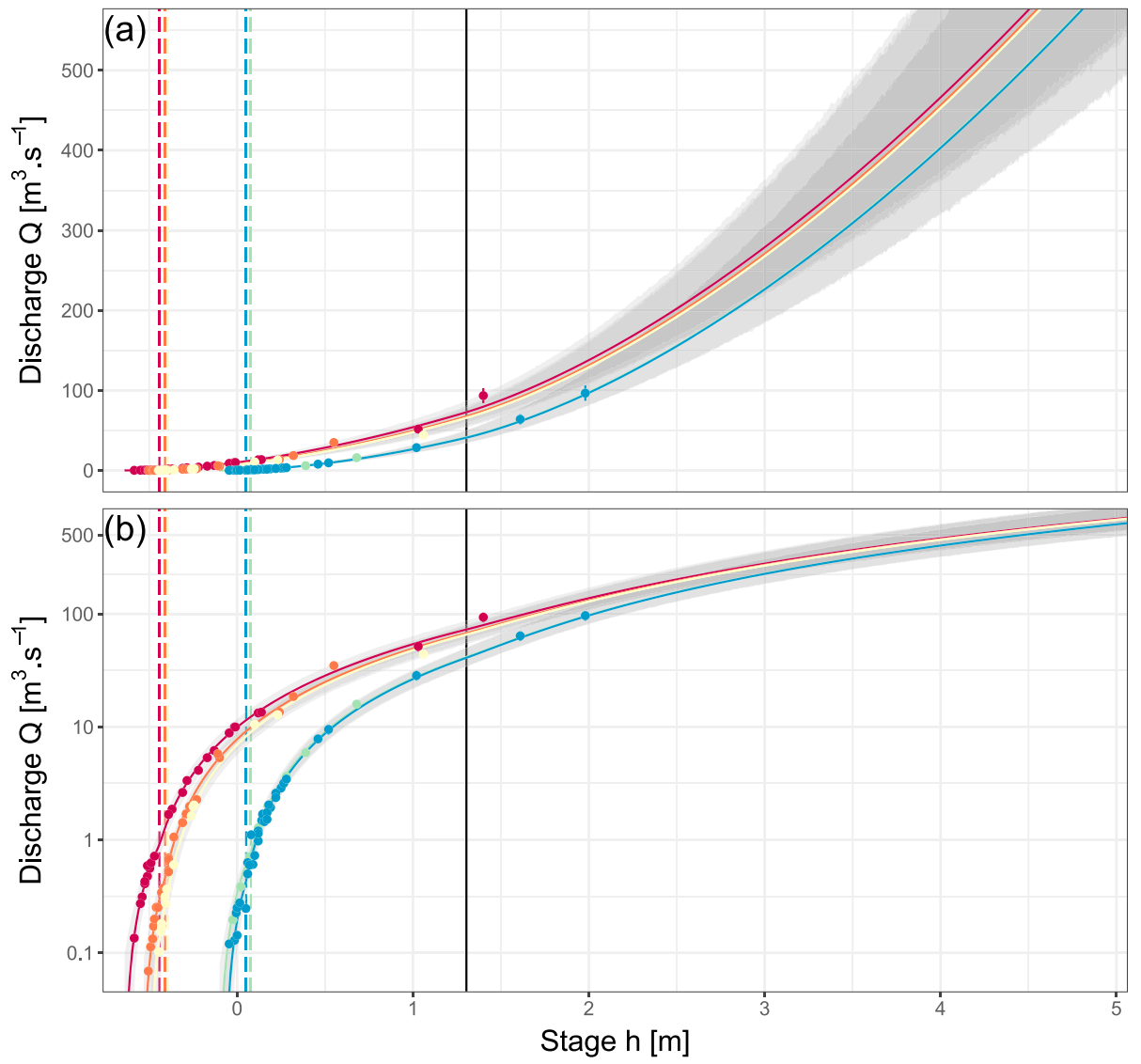

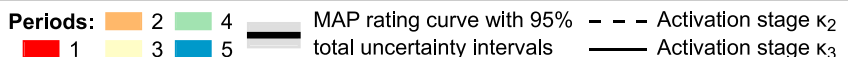

Figure 5. Ardèche case study: stage-discharge representation of the estimated stage-period-discharge model with discharge in (a) linear scale and (b) logarithmic scale. 


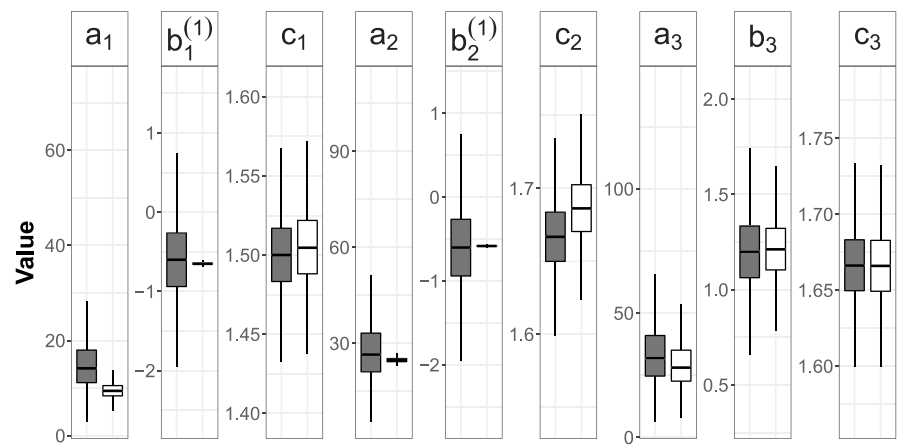

(a)

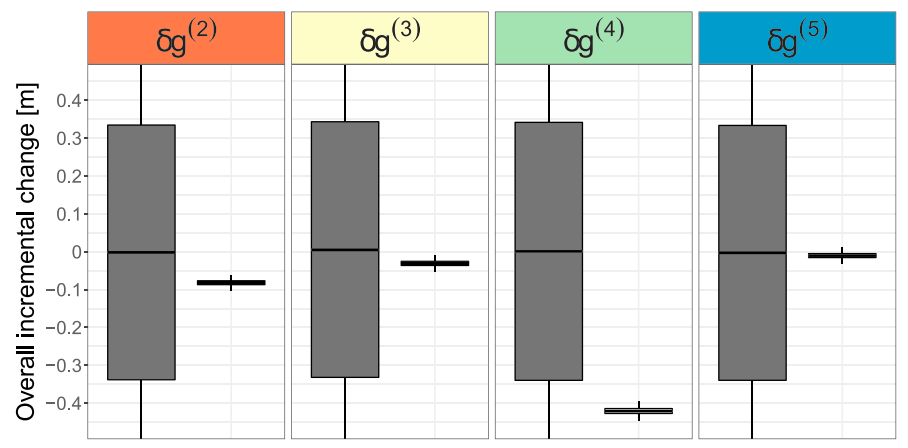

(c)

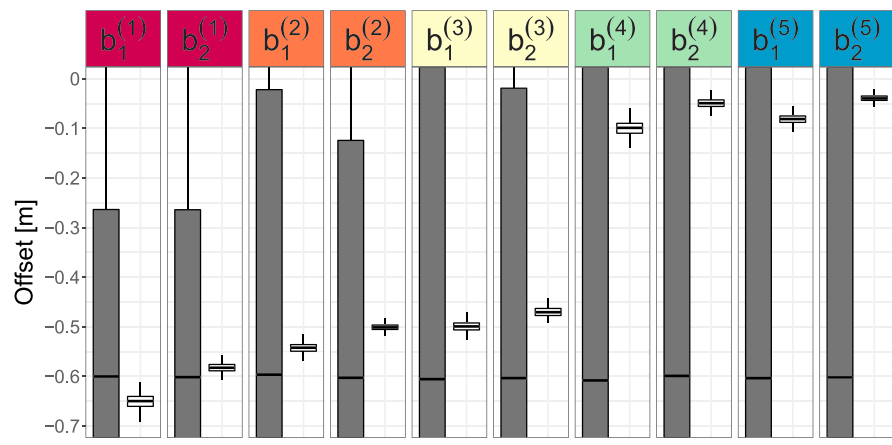

(b)

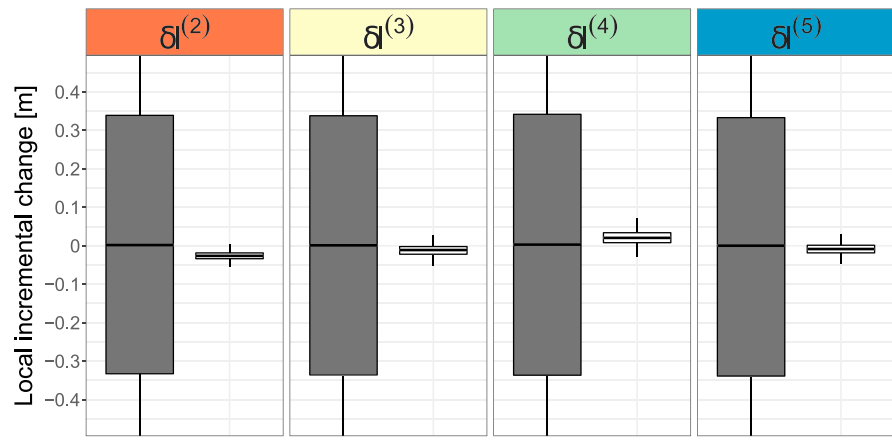

(d)

Prior $\square$ Posterior

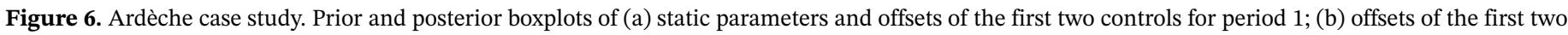
controls for all periods; (c) overall incremental changes; and (d) local incremental changes.

Figure 4 illustrates this prior transformation and shows that it induces strong correlations in the final joint prior distribution. For a given control, interperiod correlations are particularly strong: for instance, $b_{2}^{(5)}$ is highly correlated with $b_{2}^{(4)}$, which is logical since the former is equal to the latter plus the overall change $\delta g^{(5)}$. For a given period, moderate intercontrol correlations also exist: For instance, $b_{1}^{(5)}$ and $b_{2}^{(5)}$ have a correlation of 0.6 , induced by the fact that they are both affected by the same overall change. These prior correlations may play an important role in transferring information between periods (as explored in section 4.3) or between controls and are therefore important to account for. In practice this is achieved by using a multivariate Gaussian distribution as prior, fitted to the Monte Carlo sample of $\left(b_{1}^{(k)}, b_{2}^{(k)}\right)$.

\subsubsection{Results}

Figure 5 shows the estimated rating curves as stage-discharge representations with 95\% uncertainty envelopes, for the five periods. The rating curves agree well with gaugings and are estimated precisely, due to the high number of gaugings for all the periods. They are also in close agreement with official rating curves (not shown). The largest rating change occurs between periods 3 and 4 (around $0.4 \mathrm{~m}$ ), while rating changes between other periods are much smaller. Note that the hydraulic assumptions made in this case study, and more precisely the fact that the main channel control is changing, lead to nonconvergent rating curves at high flows (Figure 5a; beware of the visual artifact induced by the log scale in Figure 5b).

Figures $6 \mathrm{a}$ and $6 \mathrm{~b}$ show the estimated parameters behind these rating curves. They are in general precisely estimated, especially for the first two controls. However, the parameters $a_{3}$ and $b_{3}$ of the third control are much less precisely estimated (the posterior is similar to the vague prior) due to the scarcity of high-flow gaugings in this range. Figure $6 \mathrm{~b}$ focuses on the evolution of offsets across the five periods. All offsets are very precisely estimated (due to the availability of many gaugings), and an upward tendency is discernible (corresponding to a tendency to scouring as time advances, since periods are numbered from the most recent to the oldest). This figure also confirms that the largest change occurs between periods 3 and 4 .

Figures $6 \mathrm{c}$ and $6 \mathrm{~d}$ show the changes expressed in terms of local and overall incremental changes (which can be computed by inverting equation (15)). The rating changes are almost entirely explained by overall changes (Figure 6c), with the local changes being always precisely identified close to 0 (Figure $6 \mathrm{~d}$ ). In other 
words, the rating changes are mostly explained by changes affecting the whole main channel, while the changes affecting the low flow riffle appear to play a negligible role. This matches with the knowledge we have of this station: Scouring of the whole channel has indeed been observed. However, we stress that the SPD model inferred this from the gaugings only, since the prior distribution we specified is the same for local and overall changes and hence does not favor any of them.

\subsection{The Wairau River at Barnett's Bank, New Zealand}

\subsubsection{Site Description}

The Wairau River at Barnett's Bank station (60109) in the northern South Island of New Zealand monitors almost the entire Wairau catchment area of 3,825 $\mathrm{km}^{2}$. It is one of the case studies of McMillan and Westerberg (2015). The gauge $\left(173^{\circ} 57^{\prime} 35^{\prime \prime} \mathrm{E}, 41^{\circ} 26^{\prime} 13^{\prime \prime} \mathrm{S}\right)$ is located $500 \mathrm{~m}$ upstream from a road bridge (cf. Figure 3b). The Wairau River is a braided/wandering river with highly mobile bed. A low-flow channel meanders between scarcely vegetated gravel bars; during floods, the bars are inundated and a wider high-flow channel confined by stopbanks takes over. Both channel controls are assumed to have wide, rectangular cross-sectional shapes. Overbank flows in the floodplain are not considered here.

This hydraulic approximation of this site is convenient and parsimonious; however, it is questionable because the actual hydraulic conditions for intermediate flows when the bars begin to be inundated are much more complex than the transition from a rectangular channel control to another one. A three-control approximation (cf. equation (4)) as applied to the Meyras case was applied to the Wairau case by Mansanarez (2016), but there was no empirical evidence that a low-flow section control is really active. Also, the divided channel approach is questionable for such a wandering channel with alternate gravel bars.

The low-flow channel is a highly mobile gravel bed and frequently changes with floods. Changes in both the bed elevation and the width of the low-flow channel have been observed: consequently, both parameters $b_{1}^{(k)}$ and $a_{1}^{(k)}$ of the first control are assumed period specific. By contrast, the high-flow channel is more stable, and we therefore make the assumption that parameters $\left(b_{2}, a_{2}, c_{2}\right)$ are static. As an aside, we also tested the assumption that the high-flow channel offset $b_{2}^{(k)}$ is period specific; however, the results came with very large uncertainties and were not convincing. They are hence not reported here.

The hydraulic assumptions discussed above lead to the following SPD rating curve equation. Given the complexity of the site, we acknowledge that this formulation has scope for improvement; however, we consider that it is a reasonable first approximation in order to demonstrate the properties of the proposed approach.

$$
Q(h, k)= \begin{cases}a_{1}^{(k)}\left(h-b_{1}^{(k)}\right)^{c_{1}}, \text { if } \kappa_{1}^{(k)} \leq h<\kappa_{2}^{(k)} & \text { (low-flow channel) } \\ a_{2}\left(h-b_{2}\right)^{c_{2}}, \text { if } h \geq \kappa_{2}^{(k)} & \text { (high-flow channel) }\end{cases}
$$

Barnett's Bank is a frequently gauged station: 270 gaugings are available between 11 August 1999 and 7 April 2015, corresponding to more than 17 gaugings per year on average. However, the low-flow control changes frequently: the station managers defined 60 stability periods, corresponding to only 4.4 gaugings per period. Thus, stable periods are seldom gauged on average despite the large number of gaugings.

4.2.2. Prior Specification

Prior specification is based on the same process as that described for the Meyras case study (section 4.1.2), and the resulting priors are given in Table 2. The only difference is the definition of incremental changes. Indeed, only the first control is assumed to change, but it can change it terms of both channel elevation and width. Incremental changes for channel elevation $\left(\delta b^{(k)}\right)$ and width $\left(\delta B_{c}^{(k)}\right)$ are therefore introduced, and their relation with inferred parameters $b_{1}^{(k)}$ and $a_{1}^{(k)}$ are given by the following equation:

$$
\left\{\begin{array}{l}
b_{1}^{(k)}=b_{1}^{(1)}-\sum_{i=2}^{k} \delta b^{(i)} \\
B_{c_{1}}^{(k)}=\frac{B_{c_{1}}^{(1)}}{\prod_{i=2}^{k} \delta B_{c}^{(i)}} \Rightarrow a_{1}^{(k)}=\frac{a_{1}^{(1)}}{\prod_{i=2}^{k} \delta B_{c}^{(i)}}
\end{array}\right.
$$

Note that a multiplicative formulation is used for parameter $a_{1}^{(k)}$ in order to ensure its positivity. As in the Meyras case study, a Monte Carlo propagation through equation (19) is used to transfer the independent 
Table 2

Prior Distributions Used in the Wairau at Barnett's Bank Case Study

\begin{tabular}{|c|c|c|c|c|}
\hline Physical parameter & Meaning & Prior & Inferred parameter & Prior \\
\hline \multicolumn{5}{|c|}{ Control 1: low-flow channel } \\
\hline$b_{1}^{(1)}(\mathrm{m})$ & Offset (period 1) & $\mathcal{N}(2 ; 0.5)$ & $b_{1}^{(1)}(\mathrm{m})$ & $\mathcal{N}(2 ; 0.5)$ \\
\hline$B_{c_{1}}^{(1)}(\mathrm{m})$ & Width (period 1) & $\mathcal{L} \mathcal{N}(\ln (50) ; 0.1)$ & $a_{1}^{(1)}\left(\mathrm{m}^{\frac{4}{3}} / \mathrm{s}\right)$ & $\mathcal{L} \mathcal{N}(3.86 ; 0.26)$ \\
\hline$K_{S_{1}}\left(\mathrm{~m}^{\frac{1}{3}} / \mathrm{s}\right)$ & Strickler coefficient & $\mathcal{L} \mathcal{N}(\ln (25) ; 0.2)$ & & \\
\hline$S_{0_{1}}(-)$ & Bed slope & $\mathcal{L} \mathcal{N}(\ln (0.00143) ; 0.25)$ & & \\
\hline$c_{1}(-)$ & Exponent & $\mathcal{N}(1.67 ; 0.025)$ & $c_{1}(-)$ & $\mathcal{N}(1.67 ; 0.025)$ \\
\hline \multicolumn{5}{|c|}{ Control 2: high-flow channel } \\
\hline$b_{2}(\mathrm{~m})$ & Offset & $\mathcal{N}(2.5 ; 0.5)$ & $b_{2}(\mathrm{~m})$ & $\mathcal{N}(2.5 ; 0.5)$ \\
\hline$B_{c_{2}}(\mathrm{~m})$ & Width & $\mathcal{L N}(\ln (200) ; 0.1)$ & $a_{2}\left(\mathrm{~m}^{\frac{4}{3}} / \mathrm{s}\right)$ & $\mathcal{L} \mathcal{N}(5.24 ; 0.26)$ \\
\hline$K_{S_{2}}\left(\mathrm{~m}^{\frac{1}{3}} / \mathrm{s}\right)$ & Strickler coefficient & $\mathcal{L} \mathcal{N}(\ln (25) ; 0.2)$ & & \\
\hline$S_{0_{2}}(-)$ & Bed slope & $\mathcal{L} \mathcal{N}(\ln (0.00143) ; 0.25)$ & & \\
\hline$c_{2}(-)$ & Exponent & $\mathcal{N}(1.67 ; 0.025)$ & $c_{2}(-)$ & $\mathcal{N}(1.67 ; 0.025)$ \\
\hline \multicolumn{5}{|c|}{ Incremental changes $(2 \leq k \leq 60)$} \\
\hline$\delta b^{(k)}(\mathrm{m})$ & Offset change & $\mathcal{N}(0 ; 0.2)$ & $b_{1}^{(k)}(\mathrm{m})$ & See text \\
\hline$\delta B_{c}^{(k)}(\mathrm{m})$ & Width change & $\mathcal{L N}(\ln (1) ; 0.25)$ & $a_{1}^{(k)}\left(\mathrm{m}^{\frac{4}{3}} \cdot s^{-1}\right)$ & See text \\
\hline \multicolumn{5}{|c|}{ Structural uncertainty parameters } \\
\hline$\gamma_{1}\left(\mathrm{~m}^{3} / \mathrm{s}\right)$ & Intercept & $\mathcal{L N}(\ln (1) ; 1)$ & $\gamma_{1}\left(\mathrm{~m}^{3} / \mathrm{s}\right)$ & $\mathcal{L N}(\ln (1) ; 1)$ \\
\hline$\gamma_{2}(-)$ & Slope & $\mathcal{L} \mathcal{N}(\ln (0.5) ; 1)$ & $\gamma_{2}(-)$ & $\mathcal{L} \mathcal{N}(\ln (0.5) ; 1)$ \\
\hline
\end{tabular}

Note. $\mathcal{N}(\mu, \sigma)$ and $\mathcal{L} \mathcal{N}\left(\mu_{\log }, \sigma_{\log }\right)$ stand for, respectively, the Gaussian distribution of mean $\mu$ and standard deviation $\sigma$, and the lognormal distribution whose logarithm has mean equal to $\mu_{\log }$ and standard deviation equal to $\sigma_{\log }$.

priors expressed in terms of incremental changes to a correlated joint prior on inferred parameters $\left(b_{1}^{(k)}, a_{1}^{(k)}\right)$.

\subsubsection{Results}

Figure 7 shows the estimated rating curves for a few selected periods. A video available as supporting information shows the evolution of the rating curve across all 60 periods. Unlike in the Meyras case study, all curves converge to a common high-flow rating curve, due to the hydraulic assumption that the high-flow channel does not change across periods. The curves agree well with gaugings for all periods. They are also in close agreement with the official ratings established by station managers (not shown): as an illustration, for the periods shown in Figure 7, the stages corresponding to discharge values of 10, 100, and 1,000 $\mathrm{m}^{3} / \mathrm{s}$ differ by less than $4 \%$ between official and SPD ratings.

This high-flow rating curve is precisely estimated because its parameters are assumed static: Gaugings from all periods hence directly contribute to their estimation. By contrast, the lower part of the rating curve is affected by numerous and sometimes large changes. The precision of its estimation strongly depends on the number of available gaugings. Well-gauged periods such as periods 25 or 29 yield a precise estimate; during poorly gauged periods such as periods 51 or 52 , the low-flow rating curve is mostly constrained by the prior distribution and is hence much more uncertain.

Figure 8 shows the evolution of period-specific parameters $a_{1}$ and $b_{1}$ across all the 60 periods, and the resulting activation stages for the high-flow control $\kappa_{2}$. It confirms that the number of available gaugings plays a key role in controlling the precision of the estimated parameters. Although there is no clear long-term trend in the evolution of parameters across periods, successive phases of continuous aggradation or degradation are discernible. In addition, periods of narrowing channel (decreasing $a_{1}$ ) tend to correspond to channel deepening (decreasing $b_{1}$ ). The figure also shows that parameters remain fairly stable during, for example, periods 3 to 8 or 41 to 48 . This suggests that the number of periods might be too large and that merging some of them would be sensible according to the gaugings. However, one has to keep in mind that the station manager's decision to start a new period might be based on information beyond the gaugings (e.g., a visual observation that the low-flow channel has changed). 

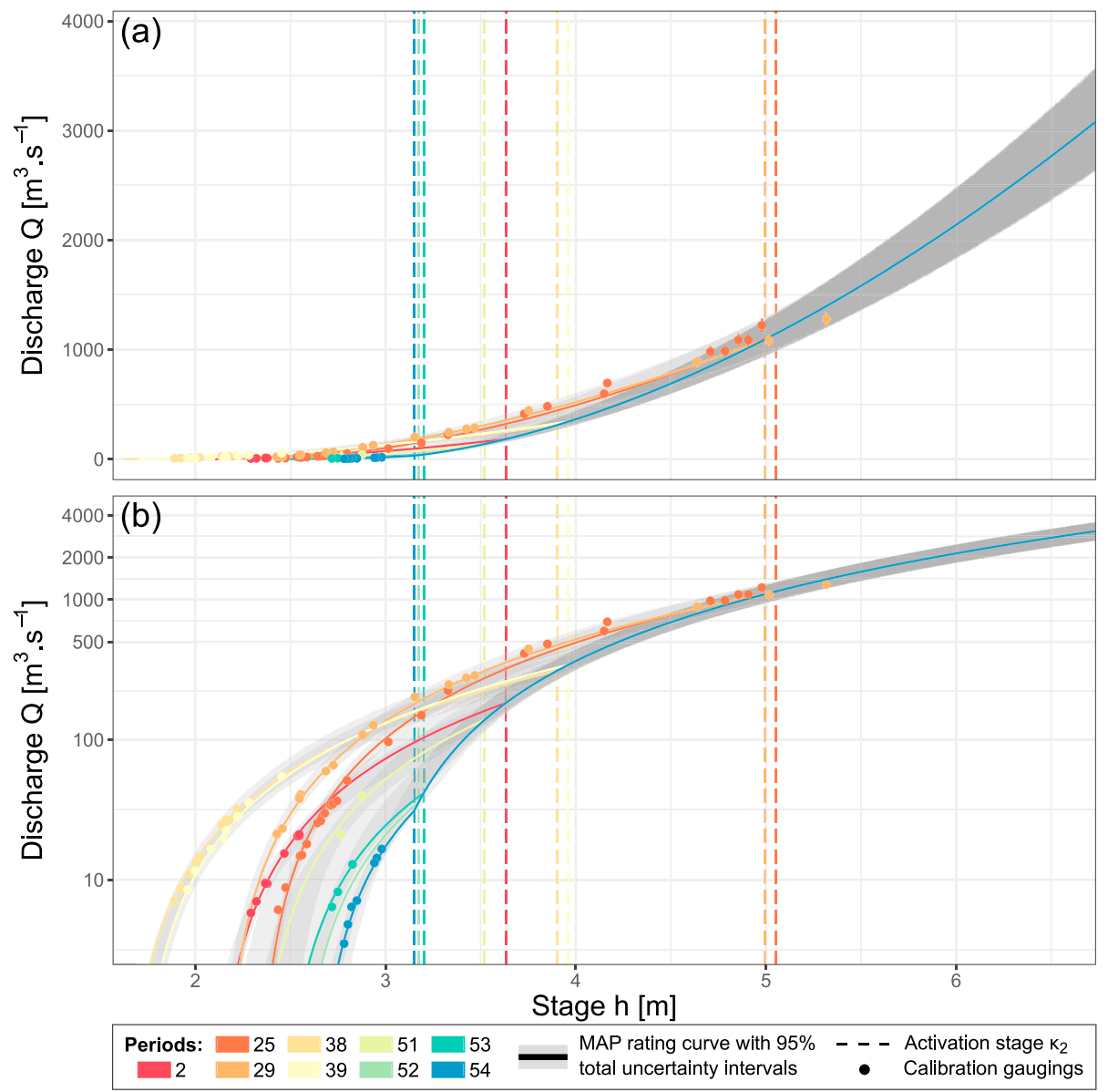

Figure 7. Wairau case study: stage-discharge representation of the estimated stage-period-discharge model for a few selected periods with discharge in (a) linear scale and (b) logarithmic scale.

\subsection{Ability of the Method to Transfer Information Between Periods}

In this section, we evaluate whether the SPD model is able to transfer information from well-gauged periods to poorly gauged ones. To this aim, data from the Meyras case study are used, and the SPD model is estimated using only the gaugings of the first period. This mimics a situation in which a period is well gauged but other periods are not gauged at all. We then evaluate whether the information gained from these gaugings transfers to the subsequent periods. In order to illustrate more clearly this transfer of information across periods, we slightly modify the prior distributions by setting the prior standard deviation of incremental change parameters (overall and local) to 0.25 (instead of 0.5 in section 4.1.2).

Figure 9a compares the prior and posterior rating curves for all the periods. For the first period, the rating curve is estimated very precisely as the posterior interval is much smaller than the prior one. This is not surprising given the high number of gaugings used for estimation in this period. The information identified on the first period propagates to subsequent periods: Posterior intervals remain smaller than prior ones for periods 2 to 5 . This can be explained at least partly by the fact that some parameters are assumed static across periods: Once such parameters have been precisely identified using the gaugings of the first period, they remain precisely identified for all subsequent periods. However, Figure 9a also suggests that the propagation of information tends to fade away as the period $k$ is further away from the first period: For the fifth period the posterior interval is much closer to the prior one than for the second period.

This can be further explained by analyzing posterior densities of the offset $b_{1}^{(k)}$ (Figure $9 \mathrm{~b}$ ). For the second period, the posterior density is still more precise than the prior one. When the period is further away from the first well-gauged period, information propagates less efficiently: The posterior distribution of the offset parameter tends to become similar to its prior distribution (see the fifth period in Figure 9b). This behavior might appear surprising at first sight: Since no gaugings from the second period were used to estimate the 


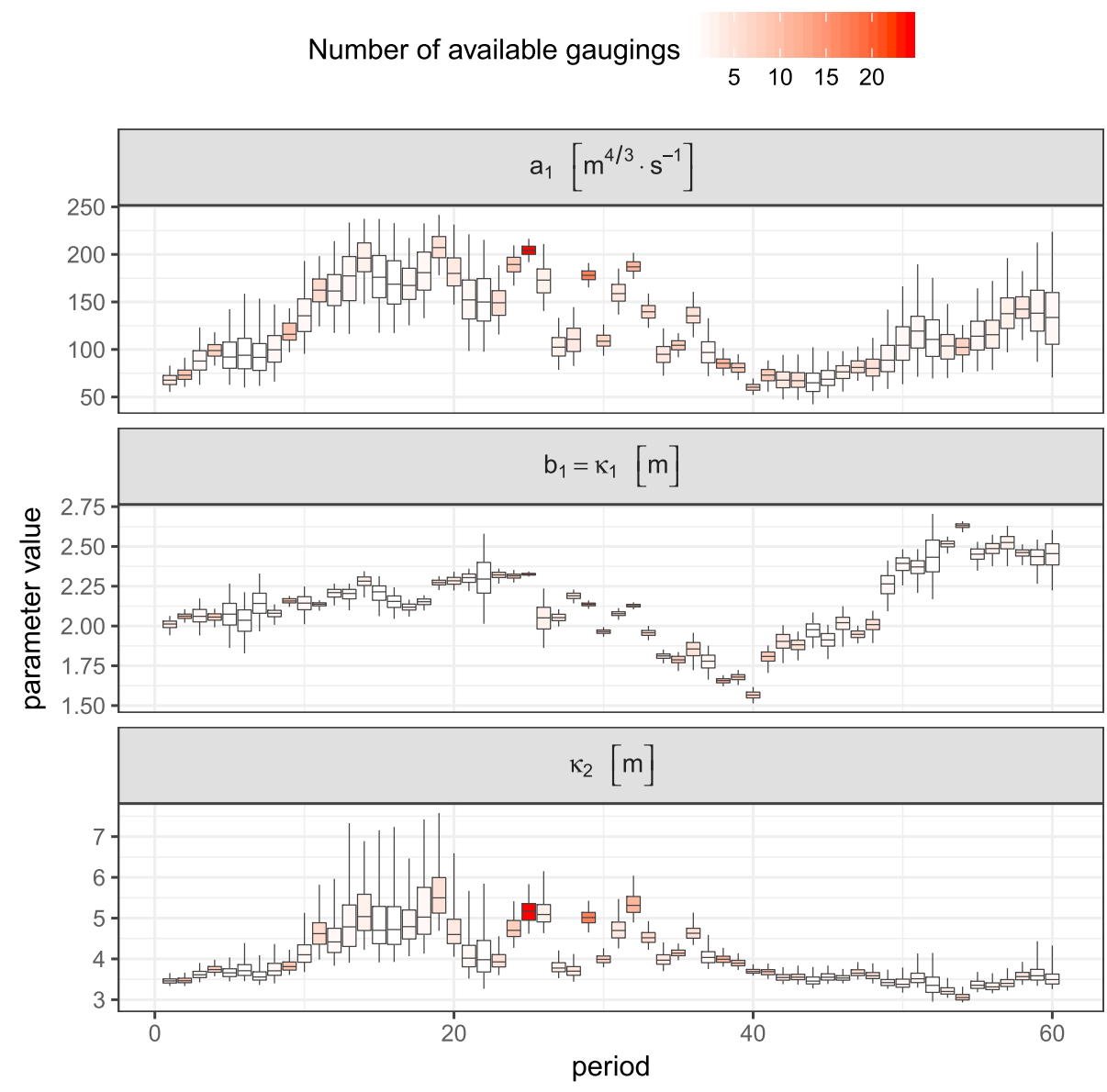

Figure 8. Wairau case study: posterior boxplots for period-specific parameters $a_{1}$ and $b_{1}$, and resulting activation stages $\kappa_{2}$.

SPD model, how can the period-specific parameter $b_{1}^{(2)}$ gain information beyond that contained in the prior? This is simply due to the fact that offsets of the first and the second periods are linked through the overall + local incremental change between periods 1 and $2: b_{1}^{(2)}=b_{1}^{(1)}-\left(\delta g^{(2)}+\delta l^{(2)}\right)$. Since $b_{1}^{(1)}$ is precisely estimated thanks to the many gaugings of period 1 , its posterior variance is much smaller than its prior one. Consequently, the posterior variance of $b_{1}^{(2)}$ is also smaller than its prior variance. The same reasoning holds for subsequent periods, since $b_{1}^{(k)}=b_{1}^{(1)}-\left(\delta g^{(2)}+\delta l^{(2)}\right)-\ldots-\left(\delta g^{(k)}+\delta l^{(k)}\right)$. However, as more terms representing incremental changes are added, the relative importance of the precisely estimated parameter $b_{1}^{(1)}$ tends to fade away. Note that for the same reason, prior uncertainty intervals also widen as the period is away from the first period, as can be seen in Figures 9a and $9 \mathrm{~b}$.

\subsection{Comparison With a Stage-Discharge Model Separately Applied to Each Stability Period} In this section, a comparison is made between the SPD model and a stage-discharge (SD) model separately applied to each stability period. Data from the Meyras case study are used for this purpose. In order to simulate poorly gauged situations, both SPD and SD models are applied considering only four gaugings per period (scarcely gauged), eight gaugings per period (reasonably gauged), or all available gaugings (very well gauged). The four and eight gaugings are evenly split between the first two controls (e.g., two gaugings for the riffle control and two gaugings for the main channel control). For the SPD model we use the same priors as in section 4.1.2. For the SD model, prior specification is made as to ensure the equivalence with the prior information used by the SPD model.

Figure 10 shows the results for the static parameters $a_{i} c_{i}, i \in \llbracket 1 ; 3 \rrbracket$, and $b_{3}$. Irrespective of the number of gaugings, both SPD and SD models yield similar results for exponent parameters $c_{1}, c_{2}$, and $c_{3}$ because their respective prior distributions are precise. Similar results are also found for parameters $a_{3}$ and $b_{3}$ of the third 
(a) Rating curves
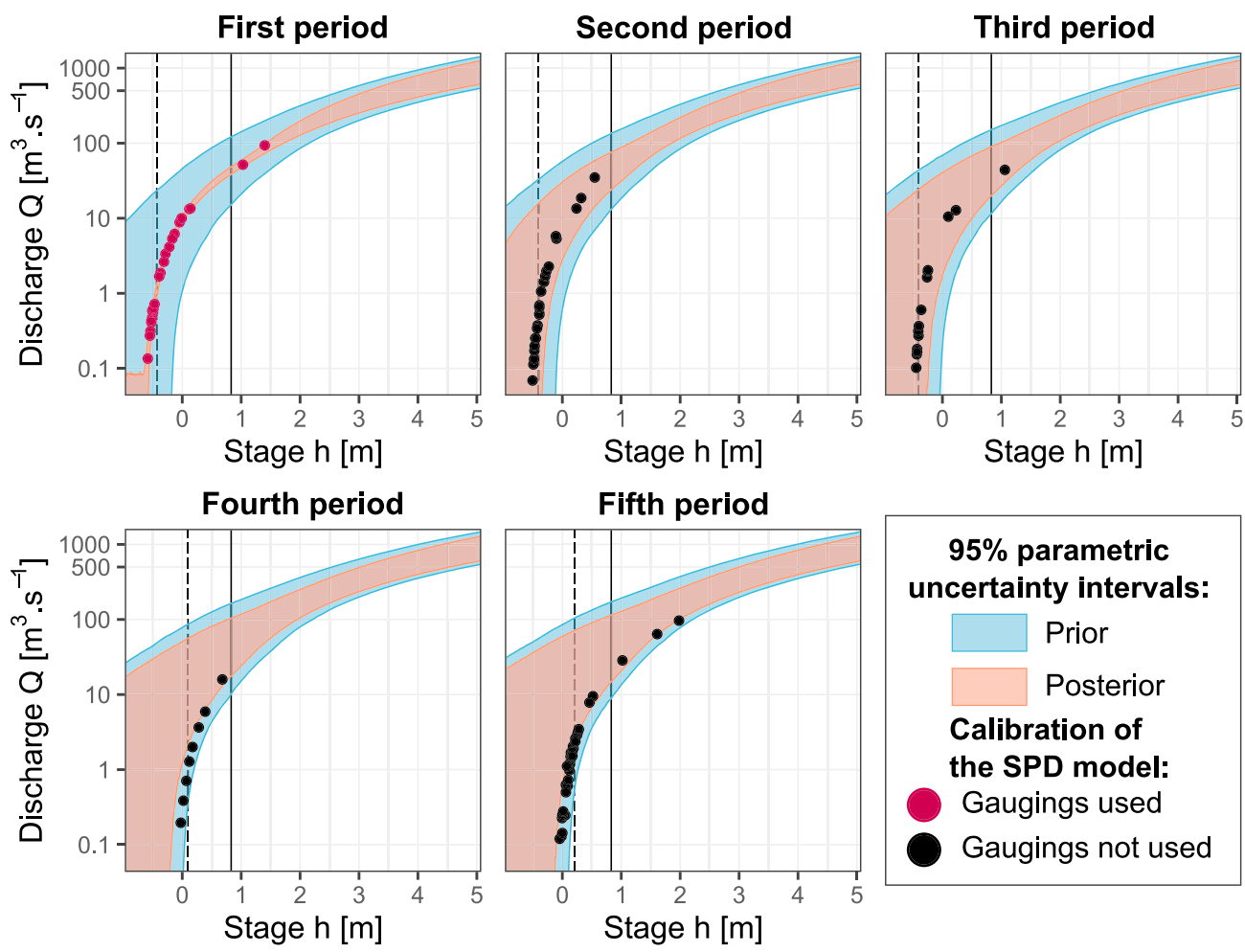

Fifth period
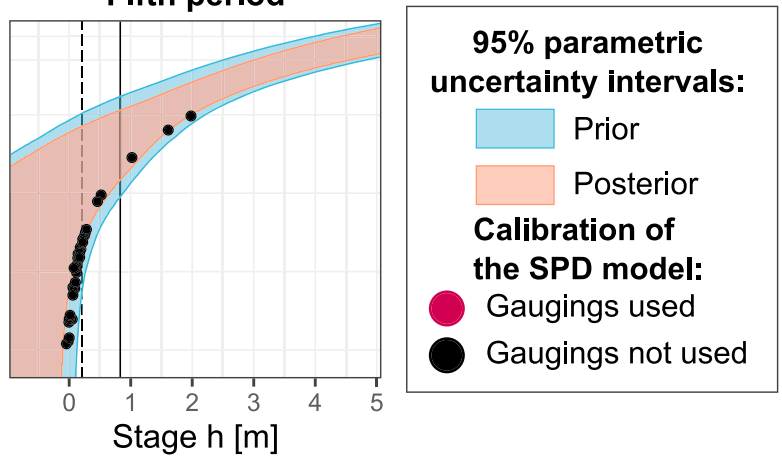

(b) Densities

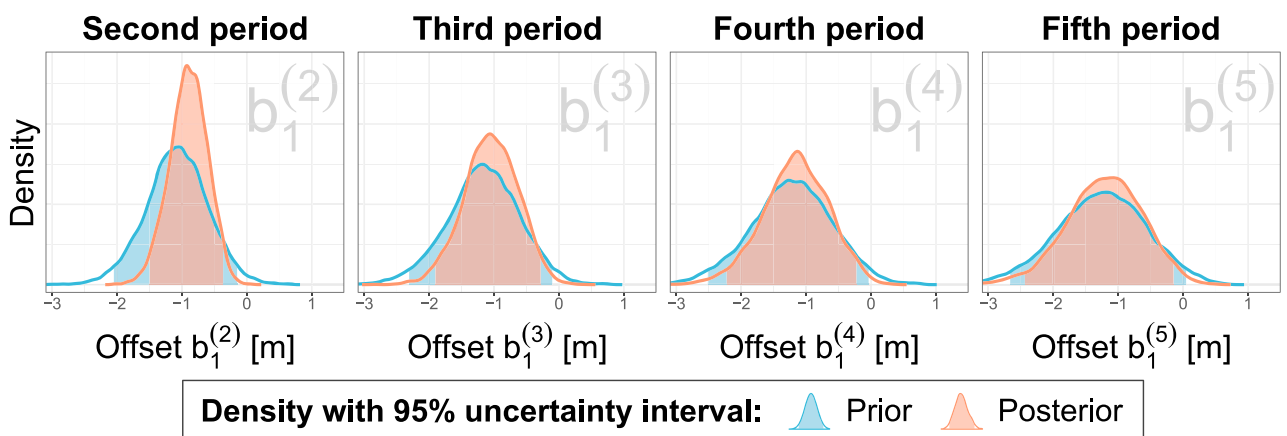

Figure 9. Ardèche case study: prior and posterior results from the SPD model using only gaugings of the first period (red) for estimation: (a) rating curves for the five periods; (b) densities of the first control offset for periods 2 to 5 with the same axis scales for all the plots. Gaugings in periods 2 to 5 (colored in black) are shown for verification but have not been used for estimation. SPD = stage-period-discharge.

control: both posterior distributions are similar to the priors. There is indeed not enough high-flow gaugings to precisely identify these parameters (see section 4.1.1).

When the station is scarcely gauged (four gaugings per period), important differences between SPD and SD models can be seen for coefficients $a_{1}$ and $a_{2}$. Estimations made by the SPD model are much more precise (Figure 10) as these parameters are assumed constant across periods. Their estimation is therefore informed by all the gaugings of the five periods (20 gaugings) instead of only four gaugings for the SD model. Similar differences between SPD and SD models are observed as the number of gaugings increases. As an aside, Figure 10 also supports the assumption made by the SPD model that these parameters are constant across periods. Indeed, for all static parameters, posterior distributions obtained with the SD model are consistent across periods. This is the case for rating curve parameters $\left(a_{i}, c_{i}, i \in \llbracket 1 ; 3 \rrbracket\right.$ and $\left.b_{3}\right)$ as well as for parameters of the structural error model $\left(\gamma_{1}\right.$ and $\left.\gamma_{2}\right)$. Moreover, the SPD model yields more precise 


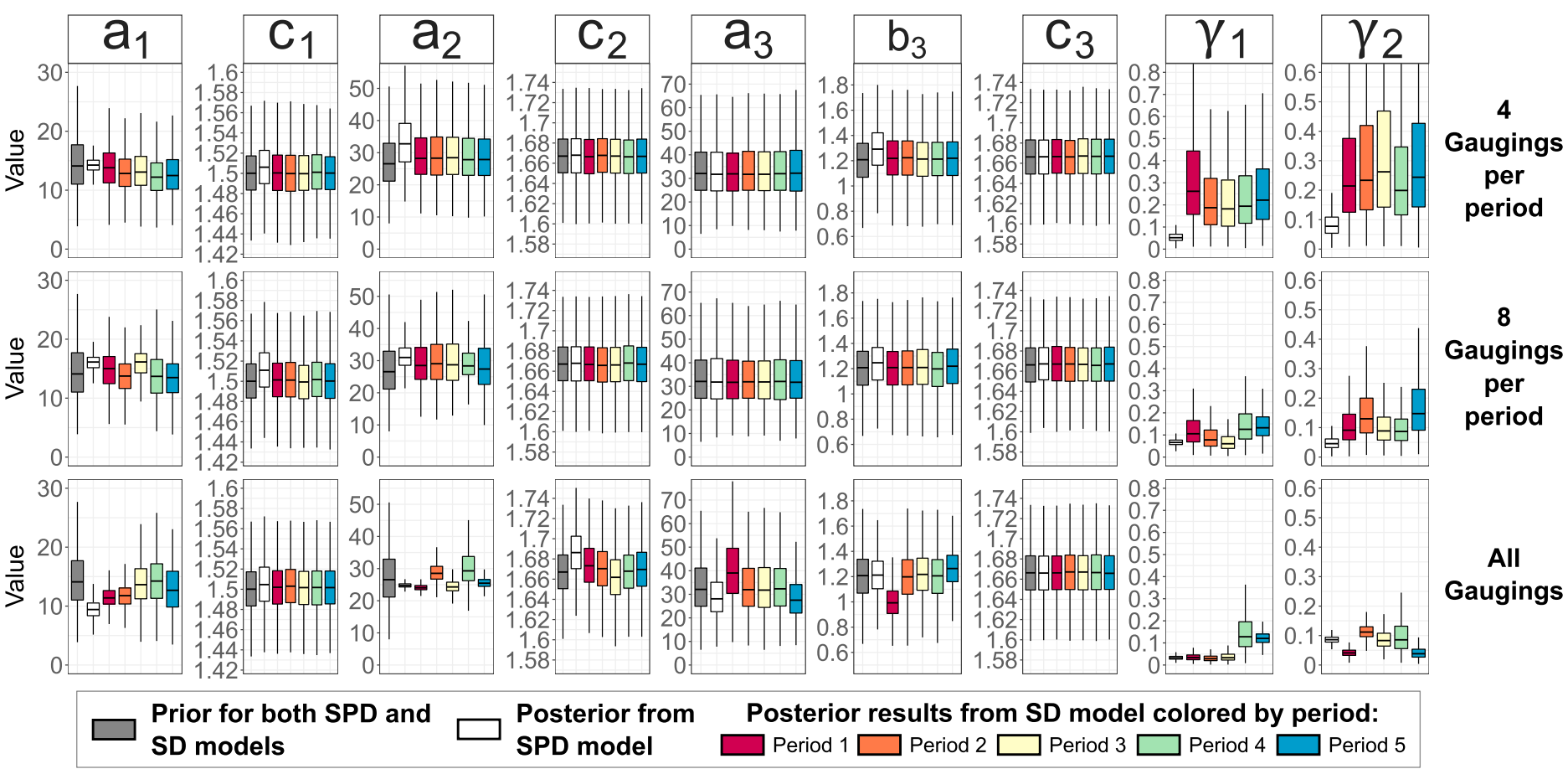

Figure 10. Ardèche case study: comparison between SPD and SD models for static parameters, using only four gaugings per period, eight gaugings per period, and all available gaugings. SPD = stage-period-discharge; $\mathrm{SD}=$ stage-discharge.

estimations of the structural error model as its parameters are estimated with more gaugings ( 5 times as many for this comparison) than for the five separate applications of the SD model.

\section{Discussion}

\subsection{Estimating the Times of Rating Changes}

The SPD model presented in this paper assumes that the stability periods are known. This is admittedly a strong assumption that requires some preliminary analyses to define these periods. We stress however that methods do exist for this purpose (see the literature review in section 1). They are mostly based on some statistical analysis of the available gaugings. While this is indisputably a valuable source of information, gaugings do not directly relate to the hydraulic processes that caused the change-instead, gaugings expose the consequences of these processes. We claim that the stage record may be another valuable source of information (see also the discussion in Reitan \& Petersen-Øverleir, 2011) and has the advantage of being more directly related to the hydraulic processes causing the changes. More precisely, the stage record could be used in two distinct ways: (i) A marked change affecting the low flow control is often clearly visible in the lowest part of the stage record, and (ii) an analysis of the cumulative sediment transport capacity of the river (e.g., Meyer-Peter \& Müller, 1948) may provide a threshold above which bed evolution may be initiated. Interestingly, such approaches could be used not only to detect changes but also to provide a prior estimate of their magnitudes.

In addition, we stress that assuming known stability periods does not exempt from exerting a critical evaluation of their definition and does not prevent from modifying them if empirical evidence suggests it. For instance, in the Meyras case study of section 4.1, the differences between periods 4 and 5 are very small, with barely distinguishable rating curves and near-zero change parameters: It would be sensible to merge these two periods into a single one. A similar observation was made for the Wairau case study of section 4.2.

An interesting avenue would be to develop a probabilistic treatment of the periods, that is, assuming that a change occurs with some probability, to be estimated. Such approach would be particularly relevant to the context of real-time estimation of rating curves and streamflows. 


\subsection{Extensions of the SPD Model}

The SPD model proposed in this paper makes a few restrictive hypotheses that could be generalized. For instance, the rating curve equation is based on the basic power law control equation $Q(h)=a(h-b)^{c}$ : This could be extended to consider different functions of stage $h$, for example, the Manning-Strickler equation derived for a narrow rectangular channel or a trapezoidal channel. Moreover, complex rating curves taking other inputs in addition to stage could be made period dependent, so as to develop stage-fall-period-discharge models from stage-fall-discharge models for sites influenced by variable backwater (Mansanarez et al., 2016; Petersen-Øverleir \& Reitan, 2009) or stage-gradient-period-discharge models from stage-gradient-discharge models for hysteresis during unsteady flows (Mansanarez, 2016; Petersen-Øverleir, 2006). Thus, complex hydraulic controls and their potential shifts across successive periods of time could be estimated through a unique model.

Other hypotheses of the SPD model are more challenging to generalize. In particular, the creation or deletion of controls is difficult to consider within a fully general framework because it modifies the structure of the rating curve equation. Moreover, we also made the assumption that the properties of structural errors do not change across periods. In principle, this could be avoided by defining period-specific parameters for the structural errors. However, in the absence of precise prior information on these parameters, a relatively high number of gaugings in all periods would be necessary to identify them, as illustrated in section 4.4. This may be problematic in cases where some periods are poorly gauged or even not gauged at all, which is a typical case in gravel bed rivers such as the Wairau River (see section 4.2).

\subsection{Using Alternative Sources of Prior Information for Rating Changes}

In this paper, expert's knowledge was used to specify prior distributions on the parameters controlling incremental changes between two successive periods. Several alternative sources of prior information could be used for this purpose. For instance, channel bathymetry profiles provide direct prior information on period-specific parameters of the rating curve. Ideally, such profiles would result from topographic campaigns; however, the gaugings themselves contain bathymetry information that could be useful, although it should be used with caution since the gauging cross section is not necessarily representative of the average channel geometry. Alternatively, the stage record also contains useful information. Indeed, large rating shifts are often visible in the stage record, and materialize as a step change in the lowest stage values. In the Meyras case study of section 4.1, for instance, the large shift between periods 3 and 4 is clearly visible as a step change in the stage record (not shown); moreover, the amplitude of this step change corresponds quite closely to the change estimated by the SPD model from the gaugings $(\approx-0.4 \mathrm{~m})$. This suggests that the stage record might be a valuable source of information to specify more informative priors on the change magnitude. Finally, an analysis of the sediment transport capacity may provide some information on the possible change in the main channel after a morphogenic flood.

\subsection{Comparison With Existing Approaches}

The SPD model introduced in this paper may be seen as a more general and more hydraulically based expression of the shift corrections (cf. section 1.2) manually implemented by several hydrometric agencies around the world. The typical constant, knee bend, and truss shift curves can be reproduced through this model, as well as other types of corrections such as changes in the coefficients. Usefully, the assumed rating corrections are directly related to physical parameters of the controls, and their estimation using limited prior knowledge and uncertain gaugings can be done in a formal, automated, and reproducible way, as opposed to manually. As a consequence, the resulting rating curves and streamflow data (and their uncertainty bounds) are easier to defend and to review.

The SPD model shares the notion of static versus varying parameters with several existing methods (Guerrero et al., 2012; Juston et al., 2014; Reitan \& Petersen-Øverleir, 2011). In the SPD model, the choice of static parameters is linked with specific hypotheses about which properties of hydraulic controls are subject to change (see also the discussion in Reitan \& Petersen-Øverleir, 2011), whereas this choice was rather based on goodness-of-fit considerations in the above mentioned papers. While both approaches are perfectly legitimate in our opinion, we stress that the expertise of a station manager may be sufficient to make this choice without even looking at the gaugings. For instance, a station manager is in general able to tell whether or not the width of the main channel has changed after a morphogenic flood, and this information can be used to build the adequate SPD model. 
The use of static versus varying parameters has several decisive advantages compared to other approaches in our opinion. First of all, it simplifies the use of gaugings: all gaugings are always assigned to a unique period, and no gauging is repeatedly used across periods. High-flow gaugings remain informative for high-flow controls of all periods as long as these controls comprise static parameters, but this is a built-in property and it does not require making any assumption beyond the hydraulic assumptions made to build the SPD model. Likewise, the high-flow convergence (or lack thereof) of rating curves from all periods is a direct consequence of these hydraulic assumptions. As illustrated in the cases studies, an SPD model assuming that only the low-flow control is subject to change will naturally lead to convergent rating curves; however, an SPD model assuming that a main channel is also varying will not.

Finally, the SPD model is specific to sudden changes and cannot be generalized to continuous changes for which dynamic approaches are probably more appropriate. As already mentionned by Reitan and Petersen-Øverleir (2011), combining dynamic and SPD-like models may lead to a more realistic description of rating changes. In particular, such a combination could be of interest to describe the transient change occurring during a morphogenic flood, thus making the transition between two stability periods. This would circumvent the difficulty related to the definition of the precise beginning of a stability period (during the rising limb, the falling limb, or at the flood peak?).

\section{Conclusion}

The main objectives of this paper were to derive, estimate, and evaluate a SPD model adapted to unstable rivers (see section 1.3). The SPD model assumes that the dates of change have been preliminarily identified and therefore uses the period index as input variable (in addition to stage). Based on the prior knowledge a field hydrologist usually has on her/his hydrometric station, the model can be built from simple hydraulic equations. The user also specifies which parameters are static and which parameters may vary across periods, and what might be the magnitude of their changes. This results in a single model that is valid over all periods: Estimation can therefore be performed in one go, instead of period after period. Bayesian inference is used for this purpose, which allows incorporating existing prior knowledge on the properties of the hydraulic controls and their changes; it also yields a natural and built-in quantification of uncertainties.

The generality of the method was demonstrated through two contrasting case studies. They were selected because the corresponding hydrometric stations differ in several key aspects: (i) distinct hydraulic configurations (riffle then main channel + floodway vs. succession of two channels); (ii) distinct types of changes (change in offsets only vs. change in both offset and channel width); (iii) distinct rating curve properties (nonconvergent vs. convergent rating curves); and (iv) different numbers of stability periods (5 vs. 60). In addition, specific experiments demonstrated the ability of the SPD model to transfer information across periods. Consequently, rating curves are more precisely estimated than by separately estimating SD models for each period.

We claim that the proposed method brings a practical solution for developing hydrometric rating curves in unstable rivers. The underlying approach, based on simple hydraulics equations, is more transparent and actually easier to specify than the empirical and graphical approaches traditionally followed (see section 1). It does not require going beyond a few explicit hydraulic assumptions on the elementary controls of the rating curve. In particular, the convergent/nonconvergent nature of rating curves is just a consequence of these assumptions; the management of gaugings is straightforward since a gauging is always assigned to a single period and is used only once. Finally, Bayesian parameter estimation is also easier and more transparent than manual fits constrained by informal expert knowledge. It also provides a simple way to compute uncertainty intervals from the large number of parameter sets simulated through MCMC sampling of the posterior distribution.

The SPD model provides a firm basis for building a more complete approach in which the times of changes would be inferred in addition to their magnitude. This would be particularly useful for long-term retrospective analysis of streamflow records at unstable sites, as well as real-time applications such as flood forecasting or hydraulic structure operation. 


\section{Appendix A: Analysis of multiple solutions for the continuity equation}

When a control $j$ replaces an existing control $j-1$, the continuity equation has no explicit solution. In order to simplify notations, and without loss of generality, we may assume that $j=2$. The continuity condition between the two segments of the rating curve can be written as follows:

$$
a_{1}\left(\kappa_{2}-b_{1}\right)^{c_{1}}=a_{2}\left(\kappa_{2}-b_{2}\right)^{c_{2}}
$$

Taking the logarithm of each side of equation (A1) for computational convenience, activation stage $\kappa_{2}$ is therefore solution of the following equation:

$$
f\left(\kappa_{2}\right)=0 \quad \text { with } \quad f(x)=c_{2} \log \left(x-b_{2}\right)-c_{1} \log \left(x-b_{1}\right)-\log \left(a_{1} / a_{2}\right)
$$

Equation (A2) is only defined for $x>\max \left(b_{1} ; b_{2}\right)$ and therefore has to be solved on the interval ] $\max \left(b_{1} ; b_{2}\right) ;+\infty$ [. In practice, since a numerical method (e.g., Newton-Raphson) is used to solve the equation, an upper bound needs to be specified as well. For the highest control, this is taken as $h_{\max }$, the upper bound of the range of validity of the rating curve; otherwise, this is taken as the activation stage of the next control.

When $c_{1}=c_{2}$ (case I), the continuity equation has a unique, explicit solution:

$$
\kappa_{2}=\frac{b_{2} a_{2}^{1 / c_{1}}-b_{1} a_{1}^{1 / c_{1}}}{a_{2}^{1 / c_{1}}-a_{1}^{1 / c_{1}}}
$$

Likewise, when $b_{1}=b_{2}$ (case II), the unique, explicit solution is

$$
\kappa_{2}=b_{1}+\left(\frac{a_{1}}{a_{2}}\right)^{\frac{1}{c_{2}-c_{1}}}
$$

In other cases, the variation of function $f(x)$ depends on the sign of its derivative $f^{\prime}(x)$ :

$$
f^{\prime}(x) \geq 0 \Longleftrightarrow \frac{c_{2}}{x-b_{2}}-\frac{c_{1}}{x-b_{1}} \geq 0 \Longleftrightarrow\left\{\begin{array}{c}
x \geq \frac{c_{2} b_{1}-c_{1} b_{2}}{c_{2}-c_{1}}=x_{0} \text { if } c_{2}>c_{1} \\
x \leq x_{0} \text { if } c_{2}<c_{1}
\end{array}\right.
$$

If $x_{0} \leq \max \left(b_{1} ; b_{2}\right)$ (case III), $f(x)$ is monotonic and equation (A2) has a single solution in ] $\max \left(b_{1} ; b_{2}\right) ;+\infty$, as shown in the following variation table (obtained with $c_{2}>c_{1}$, the case $c_{2}<c_{1}$ being symetric):

\begin{tabular}{|c|cc|}
\hline$x$ & $\max \left(b_{1} ; b_{2}\right)$ & $+\infty$ \\
\hline$f^{\prime}(x)$ & + \\
\hline$f(x)$ & \\
\hline
\end{tabular}

If $x_{0}>\max \left(b_{1} ; b_{2}\right)$, the variation table of $f(x)$ is as follows (with $c_{2}>c_{1}$, the case $c_{2}<c_{1}$ being symetric):

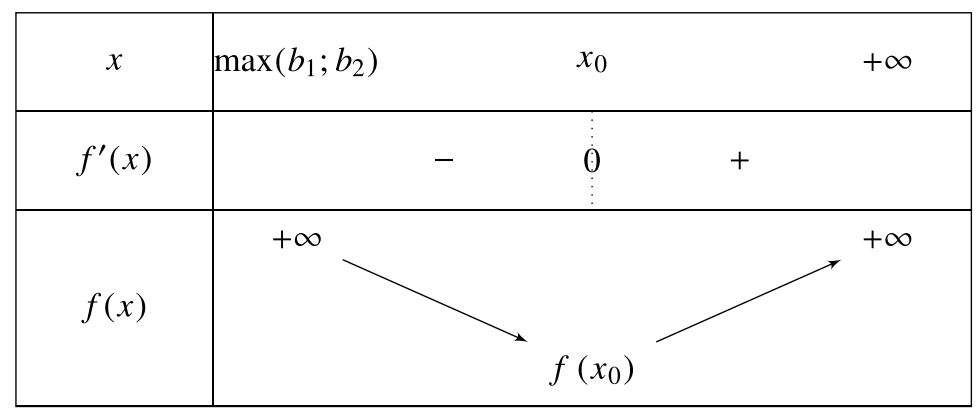




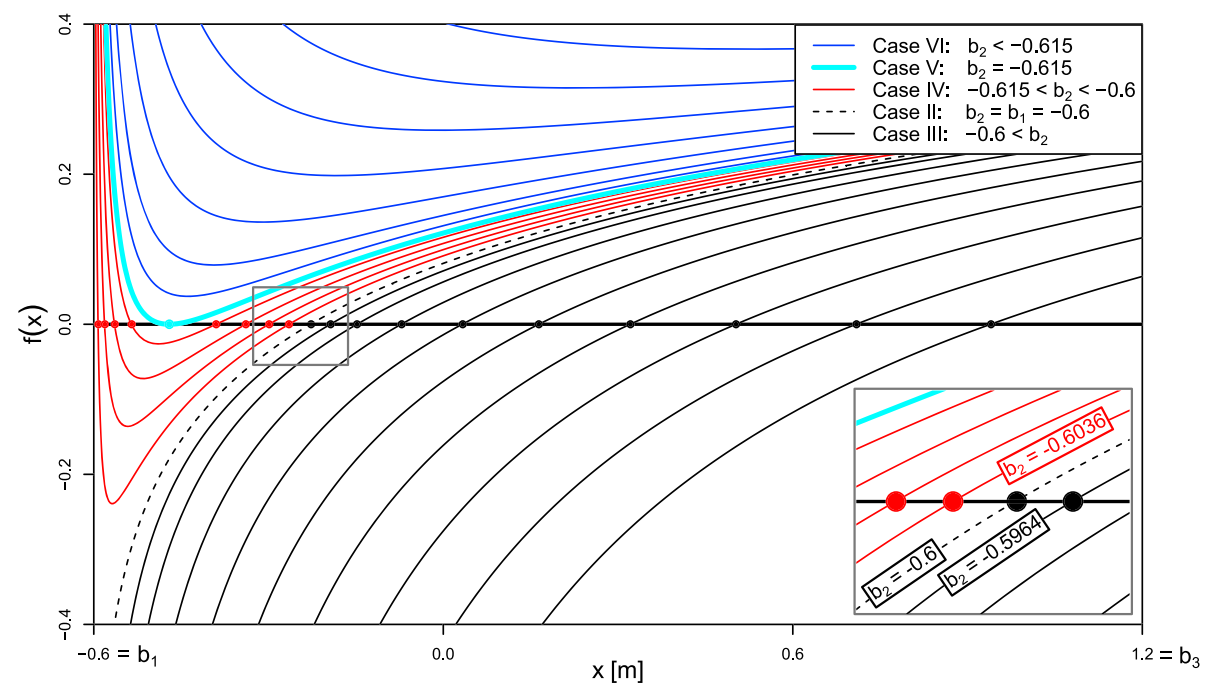

Figure A1. Continuity functions $f(x)$ for different values of $b_{2}$ and realistic values of other rating curve parameters for the Ardèche River at Meyras (cf. equations (2) and (3)): $a_{1}=21.26\left(B_{w}=12 \mathrm{~m} ; C_{r}=0.4 ; g=9.81 \mathrm{~m} / \mathrm{s}^{2}\right) ; b_{1}=-0.6$; $c_{1}=1.5 ; a_{2}=25.15\left(B_{c}=15 \mathrm{~m} ; S_{0}=0.0045 \mathrm{~m} / \mathrm{m} ; K_{S}=25 \mathrm{~m}^{1 / 3} / \mathrm{s}\right) ; c_{2}=1.67 ; b_{3}=1.2$. The box in the lower right corner zooms in on the transition between one-solution case III and two-solution case IV, illustrating the continuity of the largest case-IV solution with respect to $b_{2}$.

Acknowledgments

The PhD fellowship of V. Mansanarez was funded by Irstea and the

Compagnie Nationale du Rhône, with the support of the French National Hydrological Services (SCHAPI). The postdoctoral fellowship of $\mathrm{V}$. Mansanarez is funded by the Swedish Research Council for Environment, Agricultural Sciences and Spatial Planning (FORMAS, grant 942-2015-321). The FloodScale project was funded by the French National Research Agency (ANR) under contract ANR 2011 BS56 027, which contributes to the HyMeX program. We also wish to acknowledge the research funding provided by the Région Rhône-Alpes (Explora'doc). Data and expert knowledge on the Ardèche at Meyras station (V5004030) were provided by the French National Hydrological Services (Service de Prévision des Crues Grand Delta, Guillaume Fourquet). Data and expert knowledge on the Wairau at Barnett's Bank station (60109) were provided by the Marlborough District Council (Mike Ede) and the National Institute of Water and Atmospheric Research of New Zealand (NIWA, Kathy Walter). The data and codes used in this paper can be downloaded from Irstea's forge platform (https://forge.irstea.fr/ projects/bam/files). The codes use the DMSL Fortran library developed by Dmitri Kavetski (University of Adelaide, Australia). We finally acknowledge the constructive and insightful comments of the three anonymous reviewers of this version of the paper, as well as the feedback from the reviewers of previous versions.
If $f\left(x_{0}\right)<0$ (case IV), equation (A2) has two solutions, one in $] \max \left(b_{1} ; b_{2}\right) ; x_{0}[$ and the other in $] x_{0} ;+\infty[$.

If $f\left(x_{0}\right)=0$ (case V), equation (A2) has a single solution $\kappa_{2}=x_{0}$.

If $f\left(x_{0}\right)>0$ (case VI), equation (A2) has no solution.

Figure A1 shows continuity functions $f(x)$ computed using realistic values of rating curve parameters for the Ardèche river at Meyras. Increasing values of $b_{2}$ make the resulting functions go through cases VI, V, IV, II, and III with $0,1,2,1,1$ solutions, respectively. Case IV is the only problematic case with two solutions. However, the smallest solution can be rejected using the following continuity argument. The transition between case III (single solution) and case IV (two solutions) occurs when $b_{2}$ becomes smaller than $b_{1}$. When $b_{2}=b_{1}-\varepsilon$ for some small positive $\varepsilon$, the largest of the two case IV solutions is very close to the unique case II solution obtained for $b_{2}=b_{1}$ (see zoomed-in box in Figure A1). By contrast, the smallest solution suddenly appears much farther away, creating a discontinuity that makes no physical sense. In hydraulics terms, a tiny lowering of the channel should not drastically modify its activation stage, as the smallest solution does. Hence, as a general rule for case IV, the smallest solution is rejected and the greatest solution is retained as the correct solution. The same rule holds for the case $c_{2}<c_{1}$, which is symmetric to the case $c_{2}>c_{1}$ illustrated above.

It is important to account for potential multiple solutions for the activation stage from the discharge continuity equation (equation (A1)) and to establish the general selection rule to ensure the physical consistency of the results. In practical cases, however, the occurrence of multiple solutions may be negligible: For the Meyras case study, cases with two solutions occur in $0.4 \%$ of the MCMC samples from the posterior distribution.

\section{References}

Adamovic, M., Braud, I., Branger, F., \& Kirchner, J. W. (2015). Assessing the simple dynamical systems approach in a Mediterranean context: Application to the Ardèche catchment (France). Hydrology and Earth System Sciences, 19, 2427-2449. https://doi.org/10.5194/ hess-19-2427-2015

Balasch, J. C., Ruiz-Bellet, J. L., Tuset, J., \& Martín de Oliva, J. (2010). Reconstruction of the 1874 Santa Tecla's rainstorm in western Catalonia (NE Spain) from flood marks and historical accounts. Natural Hazards and Earth System, 10, 2317-2325. https://doi.org/10. 5194/nhess-10-2317-2010

Coxon, G., Freer, J., Westerberg, I. K., Wagener, T., Woods, R., \& Smith, P. (2015). A novel framework for discharge uncertainty quantification applied to 500 U.K. gauging stations. Water Resources Research, 51, 5531-5546. https://doi.org/10.1002/2014wr016532

Di Baldassarre, G., \& Claps, P. (2011). A hydraulic study on the applicability of flood rating curves. Hydrology Research, 42(1), 10-19. https:// doi.org/10.2166/nh.2010.098 
Di Baldassarre, G., Laio, F., \& Montanari, A. (2012). Effect of observation errors on the uncertainty of design floods. Physics and Chemistry of the Earth, Parts $A / B / C, 42-44,85-90$. https://doi.org/10.1016/j.pce.2011.05.001

Ferreira da Silva, A. M., \& Yalin, M. S. (2017). Fluvial processes, Series: IAHR Monographs (2nd ed., pp. 266). London: CRC Press. ISBN 9781138001381.

Guerrero, J.-L., Westerberg, I. K., Halldin, S., Xu, C.-Y., \& Lundin L.-C. (2012). Temporal variability in stage-discharge relationships. Journal of Hydrology, 446-447, 90-102. https://doi.org/10.1016/j.jhydrol.2012.04.031

Hamilton, A. S., \& Moore, R. D. (2012). Quantifying uncertainty in streamflow records. Canadian Water Resources Journal, 37(1), 3-21.

Herschy, R. W. (1995). Streamflow measurement. London: E \& FN Spon.

Hubert, P., Carbonnel, J.-P., \& Chaouche, A. (1989). Segmentation des séries hydrométéorologiques-Application à des séries de précipitations et de débits de l'Afrique de l'Ouest. Journal of Hydrology, 110, 349-367. https://doi.org/10.1016/0022-1694(89)90197-2

Ibbitt, R. P., \& Pearson, C. P. (1987). Gauging frequency and detection of rating changes. Hydrological Sciences Journal, 32(1), 85-103. https://doi.org/10.1080/02626668709491164

Juston, J., Jansson, P.-E., \& Gustafsson, D. (2014). Rating curve uncertainty and change detection in discharge time series: Case study with 44-year historic data from the Nyangores River, Kenya. Hydrological Processes, 28(4), 2509-2523. https://doi.org/10.1002/hyp.9786

Kennedy, E. J. (1984). Discharge ratings at gaging stations, (p. 59): U.S. Geological Survey Techniques of Water-Resources Investigations, book 3, Alexandria. Also available at https://pubs.usgs.gov/twri/twri3-a10/

Kiang, J. E., Gazoorian, C., McMillan, H., Coxon, G., Le Coz, J., Westerberg, I. K., et al. (2018). A comparison of methods for streamflow uncertainty estimation. Water Resources Research, 54, 7149-7176. https://doi.org/10.1029/2018WR022708

Lang, M., Pobanz, K., Renard, B., Renouf, E., \& Sauquet, E. (2010). Extrapolation of rating curves by hydraulic modelling, with application to flood frequency analysis. Hydrological sciences Journal, 55(6), 883-898. https://doi.org/10.1080/02626667.2010.504186

Le Coz, J., Renard, B., Bonnifait, L., Branger, F., \& Le Boursicaud, R. (2014). Combining hydraulic knowledge and uncertain gaugings in the estimation of hydrometric rating curves: A Bayesian approach. Journal of Hydrology, 509, 573-587. https://doi.org/ 10. 1016/j.jhydrol.2013.11.016

Leonard, J., Mietton, M., Najib, H., \& Gourbesville, P. (2000). Rating curve modelling with Manning's equation to manage instability and improve extrapolation. Hydrological Sciences Journal, 45(5), 739-750. https://doi.org/10.1080/02626660009492374

Mansanarez, V. (2016). Non-unique stage-discharge relations: Bayesian analysis of complex rating curves and their uncertainties (PhD dissertation), Irstea, Grenoble Alpes University, 282 p. https://tel.archives-ouvertes.fr/tel-01495985

Mansanarez, V., Le Coz, J., Renard, B., Vauchel, P., Pierrefeu, G., \& Lang, M. (2016). Bayesian analysis of stage-fall-discharge rating curves and their uncertainties. Water Resources Research, 52, 7424-7443.

McMillan, H., Freer, J., Pappenberger, F., Krueger, T., \& Clark, M. (2010). Impacts of uncertain river flow data on rainfall-runoff model calibration and discharge predictions. Hydrological Processes, 24(10), 1270-1284. https://doi.org/10.1002/hyp.7587

McMillan, H., Seibert, J., Petersen-Øverleir, A., Lang, M., White, P., Snelder, T., et al. (2017). How uncertainty analysis of streamflow data can reduce costs and promote robust decisions in water management applications. Water Resources Research 53, 5220-5228. https://doi. org/10.1002/2016WR020328

McMillan, H. K., \& Westerberg, I. K. (2015). Rating curve estimation under epistemic uncertainty. Hydrological Processes, 29(7), 1873-1882. https://doi.org/10.1002/hyp.10419

Meyer-Peter, E, \& Müller, R. (1948). Formulas for bed-load transport, (pp. 39-64). Stockholm, Sweden: Proceedings of the 2nd Meeting of the International Association for Hydraulic Structures Research.

Morlot, T. (2014). La gestion dynamique des relations hauteur-débit des stations d'hydrométrie et le calcul des incertitudes associées. Un indicateur de gestion, de qualité et de suivi des points de mesure (PhD dissertation), Dynamic rating curve assessment for hydrometric stations and computation of the associated uncertainties: Quality and station management indicators, in French. Grenoble University, 293p.

Morlot, T., Perret, C., Favre, A.-C., \& Jalbert, J. (2014). Dynamic rating curve assessment for hydrometric stations and computation of the associated uncertainties: Quality and station management indicators. Journal of Hydrology, 517, 173-186. https://doi.org/10.1016/ j.jhydrol.2014.05.007

Naulet, R., Lang, M., Ouarda, T. B. M. J., Coeur, D., Bobée, B., Recking, A., \& Moussay, D. (2005). Flood frequency analysis on the Ardèche river using French documentary sources from the last two centuries. Journal of Hydrology, 313(1-2), 58-78. https://doi.org/10.1016/j jhydrol.2005.02.011

Ocio, D., Le Vine, N., Westerberg, I., Pappenberger, F., \& Buytaert, W. (2017). The role of rating curve uncertainty in real-time flood forecasting. Water Resources Research, 53, 4197-4213. https://doi.org/10.1002/2016WR020225

Petersen-Øverleir, A. (2006). Modelling stage-discharge relationships affected by hysteresis using the Jones formula and nonlinear regression. Hydrological Sciences Journal, 51, 365-388. https://doi.org/10.1623/hysj.51.3.365

Petersen-Øverleir, A., \& Reitan, T. (2005). Objective segmentation in compound rating curves. Journal of Hydrology, 311(1-4), 188-201.

Petersen-Øverleir, A., \& Reitan, T. (2009). Bayesian analysis of stage-fall-discharge models for gauging stations affected by variable backwater. Hydrological Processes, 23(21), 3057-3074. https://doi.org/10.1002/hyp.7417

Puechberty, R., Perret, C., \& Poligot-Pitsch, S. (2017). Charte Qualité de l'Hydrométrie-Guide de bonnes pratiques. Ministère de l'Environnement, de l'Énergie et de la Mer, 83 p.

Rainville, F., Hutchinson, D., Stead, A., Moncur, D., \& Elliott, D. (2016). qSOP-NA049-01-2016, hydrometric manual-Data computations, stage-discharge model development and maintenance. Canada: Water Survey of Canada, Environment and Climate Change Canada.

Rantz, S. E. (1982). Measurement and computation of streamflow. Volume 2: Computation of discharge. Water-Supply Paper, 2175, 631.

Reitan, T., \& Petersen-Øverleir, A. (2011). Dynamic rating curve assessment in unstable rivers using Ornstein-Uhlenbeck processes. Water Resources Research, 47, W02524. https://doi.org/10.1029/2010WR009504

Réméniéras, G. (1949). Annuaire hydrologique de la France, année 1949: L'Hydraulique des stations limnimétriques pour la mesure du débit des cours d'eau. [Hydrological annual report of France, year 1949: The Hydraulics of gauging stations for streamflow measurements (in French)], Société hydrotechnique de France.

Renard, B., Garreta, V., \& Lang, M. (2006). An application of Bayesian analysis and MCMC methods to the estimation of a regional trend in annual maxima. Water Resources Research, 42, W12422. https://doi.org/10.1029/2005WR004591

Renard, B., \& Lang, M. (2007). Use of a Gaussian copula for multivariate extreme value analysis: Some case studies in hydrology. Advances in Water Resources, 30, 897-912. https://doi.org/10.1016/j.advwatres.2006.08.001

Schumm, S. A. (1977). The fluvial system. New-York: Wiley. https://doi.org/10.1017/CBO9781139165440

Sikorska, A. E., \& Renard, B. (2017). Calibrating a hydrological model in stage space to account for rating curve uncertainties: General framework and key challenges. Advances in Water Resources, 105, 51-66. https://doi.org/10.1016/j.advwatres.2017.04.011 
Steinbakk, G. H., Thorarinsdottir, T. L., Reitan, T., Schlichting, L., Hølleland, S., \& Engeland, K. (2016). Propagation of rating curve uncertainty in design flood estimation. Water Resources Research, 52, 6897-6915. https://doi.org/10.1002/2015WR018516

Watson, M., Horrell, G., \& Doyle, M. (2016). National environmental monitoring standard: Rating curves. Construction of stage-discharge and velocity-index ratings. Version: 1.0, $154 \mathrm{p}$.

Westerberg, I., Guerrero, J.-L., Seibert, J., Beven, K. J., \& Halldin, S. (2011). Stage-discharge uncertainty derived with a non-stationary rating curve in the Choluteca River, Honduras. Hydrological Processes, 25(4), 603-613. https://doi.org/10.1002/hyp.7848

Westerberg, I. K., \& McMillan, H. K. (2015). Uncertainty in hydrological signatures. Hydrology and Earth System Sciences, 19(9), $3951-3968$.

World Meteorological Organization (2010). Manual on stream gauging. Computation of discharge WMO-No. 1044, II, 195. 